OPEN ACCESS

Edited by:

Katherine Dafforn,

Macquarie University, Australia

Reviewed by:

Peter M. J. Herman,

Delft University of Technology,

Netherlands

Sebastian Vadillo Gonzalez, University of New South Wales,

Australia

*Correspondence:

Andrew K. Sweetman

A.Sweetman@hw.ac.uk

Specialty section: This article was submitted to Marine Ecosystem Ecology,

a section of the journa

Frontiers in Marine Science

Received: 24 April 2020

Accepted: 15 July 2020

Published: 19 August 2020

Citation:

Sweetman AK, Haugland BT, Kvassnes AJS and Bolam SG (2020) Impeded Macrofaunal Colonization and Recovery Following Marine Deposition of Inert and Organically

Modified Mine-Tailings.

Front. Mar. Sci. 7:649.

doi: 10.3389/fmars.2020.00649

\section{Impeded Macrofaunal Colonization and Recovery Following Marine Deposition of Inert and Organically Modified Mine-Tailings}

\author{
Andrew K. Sweetman ${ }^{1 *}$, Barbro T. Haugland ${ }^{2}$, Astri J. S. Kvassnes ${ }^{3}$ and \\ Stefan G. Bolam ${ }^{4}$ \\ 1 Deep-Sea Ecology and Biogeochemistry Research Group, The Lyell Centre for Earth and Marine Science, Heriot-Watt \\ University, Edinburgh, United Kingdom, ${ }^{2}$ Marine Biology Division, Department of Biological Sciences, University of Bergen, \\ Bergen, Norway, ${ }^{3}$ ReStone AS, Bergen, Norway, ${ }^{4}$ The Centre for Environment, Fisheries and Aquaculture Science, \\ Lowestoft Laboratory, Lowestoft, United Kingdom
}

Fine-grain, waste rock (or tailings) produced during mining processes are the main waste product following the extraction of valuable minerals and metals from ores. The proximity of mineral resources to coastal regions in some countries has meant that the organically inert mine tailings are often deposited into the marine environment as a submarine tailings placement or STP. This creates a real environmental challenge since the deposition of tailings at the seafloor can completely smother the benthic environment and reduce benthic biodiversity and alter ecosystem function. A limited number of studies have attempted to quantify the speed of seafloor recovery following tailings disposal and have suggested that one of the main factors limiting seafloor colonization is the lack of organic matter of the tailings deposited. In this experimental study, we used hydrodynamically unbiased settlement trays within a complete randomized block design to test whether macrofaunal colonization of mine tailings, and resemblance toward ambient assemblages, is enhanced when tailings become more enriched in organic $\mathrm{C}\left(\mathrm{C}_{\mathrm{org}}\right)$. Our experiment showed that tailings with $\mathrm{C}_{\text {org }}$ contents $\geq 1 \%$ exhibited lower faunal abundance and biomass and different macrofaunal community composition after 1 year compared to background sediments. Macrofaunal species richness (defined as the total number of different taxa) in the 0 and $0.5 \% \mathrm{C}_{\text {org }}$ tailings treatments, however, was statistically indistinguishable from ambient intertidal sediments after 1 year. Furthermore, macrofaunal community structure was more similar to that of the background intertidal sediments after 1 year, which collectively suggest partial recovery of seafloor biodiversity in tailings with zero to low $\mathrm{C}_{\text {org }}$ levels. Nevertheless, macrofaunal abundance and biomass in these treatments remained significantly less than the background community after 1 year suggesting factors other than the $\mathrm{C}_{\text {org }}$ content of tailings may be structuring macrofaunal colonization and impeding seafloor recovery of tailings deposits. We propose that the non-marine physical structure of the tailings particles, which show great angularity is predominantly responsible for the observed delayed recovery.

Keywords: marine benthos, mine tailings, organic carbon, macrofauna, colonization, ecosystem recovery 


\section{INTRODUCTION}

The disposal of sedimentary material into the marine environment constitutes a significant problem in coastal zone management and, albeit often localized, represents a major anthropogenic disturbance on the benthos (Bolam et al., 2004; Ramirez-Llodra et al., 2015; Trannum et al., 2019). Since ocean disposal of industrial waste and sewage sludge has been phased out in the United Kingdom and many European countries, there is now greater focus on behalf of the public and legislative bodies on the disposal of sedimentary material such as dredged material or inert mine tailings (Vogt and Walls, 1991; Kvassnes and Iversen, 2013; Ramirez-Llodra et al., 2015). Dredging has been shown to cause negative effects on the benthos (e.g., Sanchez-Moyano et al., 2004; Robinson et al., 2005) so there is now a greater emphasis on relocating dredged material in such a way as to derive environmental or other benefits (Bolam et al., 2006; Bolam, 2014) such as creating or enhancing mudflats (Ray et al., 1994; Evans et al., 1998) and saltmarshes (Laselle et al., 1991; Posey et al., 1997). For mine tailings, the millions of tons of waste produced annually limits potential transport options so tailings tend to be disposed of in slurry form directly to the coastal environment through de-aerated pipelines (Kvassnes and Iversen, 2013; Ramirez-Llodra et al., 2015). In Norway, where this practice is routinely carried out, the coastal environments regularly affected by the deposition of mine tailings include soft-sediment fjord habitats (Kvassnes and Iversen, 2013; Trannum et al., 2018, 2019, 2020). Historically, mine tailings deposited into coastal water bodies in Norway have included both chemically inert or reactive (e.g., containing sulfides) forms, while tailings deposited today are largely chemically inert (Kvassnes and Iversen, 2013).

When mine tailings are disposed of into the marine environment the amount of material deposited is often sufficient to smother the resident infauna and sessile megafauna (Ray et al., 1994; Bolam et al., 2003; Bolam, 2012; Trannum et al., 2019), and significantly alter ecosystem function by limiting oxygen and food supply to benthic organisms (Mevenkamp et al., 2017). Exposure to toxic metals in the tailings sludge (e.g., from ores high in sulfides or process chemicals) has also been shown to negatively impact macrofauna and flora (Ramirez-Llodra et al., 2015). Any subsequent biological recovery of the tailings occurs via larval settlement and/or lateral migration by juveniles and adults (Whitlatch et al., 2001; Bolam et al., 2004); a process that for mine tailing deposits has been shown to be relatively slow (Burd, 2002; Berge et al., 2011; Trannum et al., 2020). It has been postulated that slow macrofauna colonization often documented for mine tailings results from the lack of available organic carbon $\left(\mathrm{C}_{\mathrm{org}}\right)$ that deposit-feeding fauna require for food (Kvassnes et al., 2009; Kvassnes and Iversen, 2013). As microbial abundance has been shown to correlate positively to sediment organic content (e.g., Yamamoto and Lopez, 1985), the limited faunal colonization into organically sterile tailings may also result from impaired microbial colonization that may have knock on effects on immigration rates of deposit feeders to the deposit. Surprisingly, no work has yet tested the effects of $\mathrm{C}_{\text {org }}$ content on macrofauna colonization of tailings though there is evidence to suggest that adding organic material to tailings may benefit seafloor ecosystem recovery at the end of the life of a tailings deposit. For example, Tavares et al. (2008) found strong positive and significant relationships between sediment organic matter content and the abundance of macrofaunal colonizers in a coastal lagoon in Portugal. Ford et al. (2001) found that sediment organic loading had a significant effect on the sizefrequency structure and abundance of amphipod colonizers. Finally, Bolam et al. (2004) demonstrated that macrofaunal recolonization of defaunated mudlfat sediment was significantly altered by sediment $\mathrm{C}_{\text {org }}$ though they did not explicitly assess the implications of a total absence of $\mathrm{C}_{\mathrm{org}}$ on faunal colonization as would be the situation for freshly deposited inert mine-tailings. However, while it is plausible that the addition of $\mathrm{C}_{\text {org }}$ to tailings may enhance macrofauna recovery, adding excessive amounts of organic material may also hinder macrofauna recovery due to the excessive build-up of toxic metabolic by-products in sediment porewaters and their effects on colonizing fauna (Hyland et al., 2005). Clearly, a better understanding of how colonization processes change in relation to the organic content of tailings would be beneficial for the management of coastal environments exposed to tailings deposits, potentially reducing the detrimental ecological consequences of this practice.

To address the current paucity in knowledge, we conducted a manipulative field experiment on an intertidal mudflat habitat to investigate the effect of adding different levels of $\mathrm{C}_{\mathrm{org}}$ to mine tailings on macrofaunal colonization. We specifically compared data on macrofaunal abundance, biomass, diversity and community structure in the tailings experiments over time with those of the adjacent mudflat to assess if the macrofaunal communities that colonize tailings are able to recover to predisturbance conditions in 1 year, and assess how the organic content of the tailings regulates the colonization process. By comparing the tailings data to background soft sediments, our results have broad implications and provide an ecologically meaningful reference point for temperate soft-sediment habitats exposed to mine tailings deposits. We specifically tested the null hypotheses $\left(\mathrm{H}_{\mathrm{o}}\right)$ that macrofaunal abundance, biomass, diversity and community structure in tailings enriched by $<1 \%$ $\mathrm{C}_{\text {org }}$ do not show any significant difference to background sediments in 1 year, in contrast to tailings with greater concentrations of $\mathrm{C}_{\text {org }}$.

\section{MATERIALS AND METHODS}

\section{Experimental Site}

We undertook our study on a soft-sediment mudflat situated on the Crouch Estuary in the United Kingdom (Figure 1). The Crouch Estuary is situated north of the Thames Estuary in Essex, South East England. It stretches about $45 \mathrm{~km}$ in land and is affected by tidal flushing $29 \mathrm{~km}$ upstream although the volume of freshwater input is generally low, so the estuary is more correctly referred to as a sea inlet (Waldock et al., 1999; Bolam et al., 2004). The experiment was set up mid-way up the sea inlet within a muddy intertidal zone $\left(51^{\circ} 38^{\prime} 22 \mathrm{~N}\right.$, $\left.00^{\circ} 42^{\prime} 39 \mathrm{E}\right)$. Although the site does not have a history of mine 

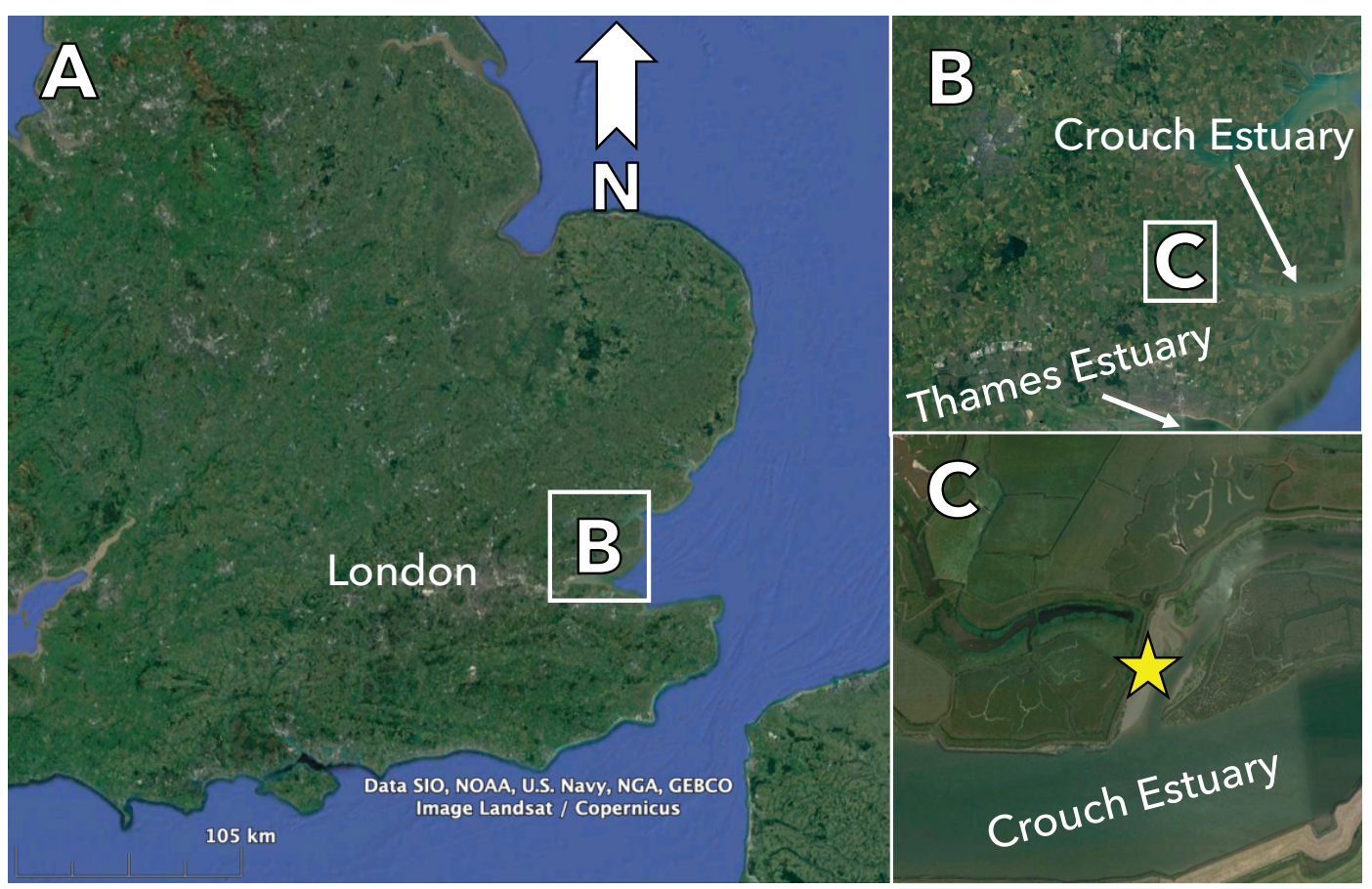

FIGURE 1 | Location of the study site (yellow star) in the Crouch Estuary in the north eastern region of the Thames Estuary in south east England, United Kingdom (Images from Google Earth@).

tailings disposal, it was selected for a number of reasons. Firstly, it was the experimental site used by Bolam et al. (2004), which assessed faunal colonization into defaunated mudflat sediments over a 1-year period. Thus, by using the site we were able to compare mine tailings colonization processes to those occurring in defaunated, background mudflat sediments. Secondly, the experimental area was naturally sheltered from strong tidal currents that would prevent winnowing of the organic matter in the tailings and erosion of sediments from the colonization trays allowing a stable and non-dynamic experimental site. The sediments at the site are characterized as fine with a silt/clay content $>90 \%$ and a $\mathrm{C}_{\text {org }}$ content between 1.5 and 1.7\% (Bolam et al., 2004). The macrofaunal community on the mudflat is dominated by the gastropod Peringia ulvae, tubificid oligochaetes and Tharyx spp. polychaetes (Bolam et al., 2004).

\section{Experimental Design and Set Up}

Although toxic mine tailings high in heavy metal concentrations (e.g., $\mathrm{Pb}, \mathrm{Zn}$ ) have been deposited in some areas around the world (e.g., Black Angel mine in Greenland), the vast majority of tailings being deposited in Norway are non-toxic in nature, with toxicity effects largely resulting from the addition of process chemicals (Ramirez-Llodra et al., 2015). Non-toxic, recently mined, azoic mine tailings were used in our experiments and were obtained from Rana Gruber AS, a mining company that extracts iron-ore (Haematite) resources from an underground mine. It has a permit to deposit $1.25 \mathrm{M}$ tons of tailings per year into Ranafjorden situated in central western Norway.
Metal content analysis on the tailings by ICP-MS and ICP-AES revealed mean copper, zinc and nickel concentrations of 34, 28, and $10 \mathrm{ppm}$, respectively. All other metal concentrations (e.g., chromium, cadmium, lead, arsenic concentrations) contributed less than $4 \mathrm{ppm}$. Ground-up commercial fish farm pellets (initial N-content: $7.7 \pm 0.0 \%[n=3]$, initial C-content: $49.5 \pm 0.4 \%$ $[n=3])$ were used as a labile $\mathrm{C}_{\text {org }}$ source in our experiments to attain tailings $\mathrm{C}_{\mathrm{org}}$ concentrations of $\sim 0.5,1,2.5$, and $5 \%$. Although fish farm feed is naturally more labile than the organic C sources (e.g., microphytobenthos) that occur naturally in estuaries and could have led to non-natural colonization dynamics, this carbon source was used as it is easily obtainable, which would increase the potential for scaling up to enriching tailings if the experiment showed enhanced colonization of organic-enriched tailings. The pellets also had a C content that was in the same order of magnitude as Ascophyllum nodosum another labile C source (C content: $31.5 \%$ ) used in previous organic enrichment colonization experiments (Widdicombe and Austen, 2001; Bolam et al., 2004). Complete mixing of the $\mathrm{C}_{\text {org }}$ source with the azoic mine tailings was ensured by using an unused cement mixer and mixing tailings with the organic material for $10 \mathrm{~min}$. Immediately after mixing, three replicate sediment samples were collected from each treatment for sediment $\mathrm{C}_{\text {org }}$ and sediment total nitrogen content (TN) and frozen at $-20^{\circ} \mathrm{C}$.

A complete randomized block design, consisting of three sampling blocks and one 'replacement' block, was established (Figure 2). Each of the sampling blocks (blocks 1-3) had seven experimental plots: four mine tailings treatments 


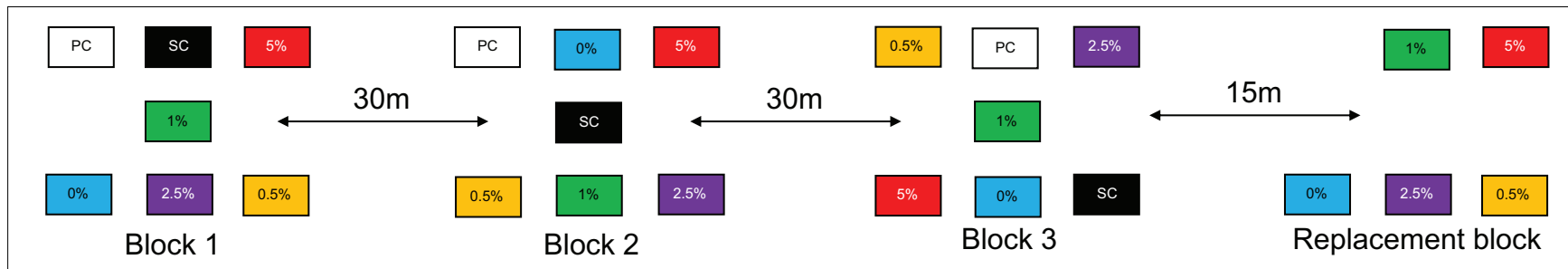

FIGURE 2 | The layout of the three sampling blocks and the replacement block at the experimental site. The blocks were set up parallel to the shore to prevent tidal elevation effects. The replacement block did not include a PC or SC treatment.

modified with the different $\mathrm{C}_{\text {org }}$ concentrations, an unmodified tailings treatment $\left(0 \% \mathrm{C}_{\mathrm{org}}\right)$ and two controls (Figure 2). One of the controls was termed a 'sampling control' (SC) to account for natural variability, as the experiment was carried out over 365 days. The other control was termed a 'procedural control' (PC) that was used to quantify potential effects caused by disturbance related to the experimental set up and the repeated sampling. The replacement block consisted of the five $\mathrm{C}_{\text {org }}$ tailings treatments (Figure 2) and provided comparable sediments to the tailings sediments in blocks 1-3. When sediments were sampled for fauna and sediment chemistry from blocks 1-3 during the experiment, replacement sediment cores were collected from the replacement block and inserted into the sampling locations of blocks 1-3 to maintain the $\mathrm{C}_{\mathrm{org}}$ concentration of the different treatments and prevent sediment from slumping into the empty space created by the coring procedure. The same procedure was done for the SC and PC samples in blocks 1-3 using background intertidal sediments collected from elsewhere on the mudflat.

The blocks were set up adjacent to each other along the shore of the mudflat to reduce potential block effects caused by the progress of tidal flushing in the estuary. The blocks were separated by $30 \mathrm{~m}$ to reduce interdependence between the replicates (Figure 2). Plastic freezer trays $\left(0.25 \mathrm{~m}^{2}\right.$ by $10 \mathrm{~cm}$ depth) were used as plots for the different treatments. Although the use of trays prevented sediments/porewaters from beneath the trays interacting with the tailings within the trays, the mixing of organic material and porewaters into surface tailings in thick tailings deposits is likely to be negligible. The use of the trays also only allowed colonization to larvae, adults and/or juvenile settlement at the sediment surface and prevented lateral migration from beneath the sediment-water interface. The use of trays therefore simulated colonization processes at in situ mine-tailings deposits where muddy seafloor sediments become completely smothered by meter-deep tailing deposits and lateral colonization from surrounding sediments is, apart from at the periphery, excluded. As previous studies have been criticized for using colonization trays that protruded above the sediment surface (Smith and Brumsickle, 1989; Snelgrove et al., 1992) and the hydrodynamics of the benthic boundary layer are important in structuring benthic settlement of shallowwater larvae, the trays were placed to ensure their tops were flush with the surrounding mudflat thereby minimizing hydrodynamic (e.g., turbulence) artifacts on colonization processes. The sediment of the control plots (SC and PC) was not modified in any way.

\section{Sampling Procedure}

The experiment was initiated on the 26th of April 2012 and completed 1 year later. Samples from the five tailings treatments were collected on four occasions at $T=45,115,180$, and 365 days. No fauna samples were collected from the tailings treatments at $T=0$ day as the tailings in the trays were recently produced and completely devoid of biota. However, the SC was sampled at $T=0$ day and on all subsequent occasions, while the PC was only sampled at $T=0$ day and $T=365$ days to test the effect of the sampling procedure on macrofaunal community structure over the duration of the experiment.

A perspex corer $\left(10 \mathrm{~cm}\right.$ int. diam.; sampling $0.008 \mathrm{~m}^{2}$ ) was used to sample the macrofauna to a depth of $10 \mathrm{~cm}$, and a smaller corer $\left(2 \mathrm{~cm}\right.$ int. diam.; $\left.0.0003 \mathrm{~m}^{2}\right)$ was used to collect samples for sediment particle size assessment (PSA) at 365 days, and $\mathrm{C}_{\mathrm{org}}$ and $\mathrm{TN}$ content samples throughout the study. The macrofaunal samples were preserved using 10\% buffered formaldehyde and the sediment for PSA, $\mathrm{C}_{\text {org }}$ content and TN were frozen at $-20^{\circ} \mathrm{C}$. Redox potential values were measured in each plot at 1,2 , and $4 \mathrm{~cm}$ depths at each sampling time using a Russell RL100 Redox Meter with a calomel probe (Pearson and Stanley, 1979).

\section{Sample Processing and Data Acquisition Macrofaunal Abundance and Biomass}

The macrofaunal samples were later washed over a $500-\mu \mathrm{m}$ mesh sieve in the laboratory and stained with Rose Bengal to aid separation of the macrofauna from the remaining sediment residue. Identification and enumeration were conducted using dissecting and compound microscopes with specimens being identified to the lowest possible taxonomic level. Individuals belonging to Polychaeta, Oligochaeta, and Gastropoda were generally identified to species level whereas those of other major taxonomic groups (e.g., Nematoda, Ostracoda, Harpacticoida) were generally identified to phylum level. Wet biomass was measured following the methods outlined in the Clean Seas Environment Monitoring Manual (CSEMP) Green Book (2012). In short, specimens were blotted and wet weight was recorded to the nearest $0.0001 \mathrm{~g}$ after first being immersed in water to rinse off as much preservative as possible. 


\section{Sediment PSA, Corg Content and TN}

Sediment samples collected for PSA at 365 days were wet sieved on a $500-\mu \mathrm{m}$ stainless steel test sieve using a sieve shaker. The $>500 \mu \mathrm{m}$ component was oven dried for $12 \mathrm{~h}$ at $80^{\circ} \mathrm{C}$ and hand sieved over a range of test sieves at 0.5 phi intervals. The sediment on each sieve was retained and weighed to the nearest $0.01 \mathrm{~g}$. The $<500 \mu \mathrm{m}$ fraction was freeze-dried and weighed and a sub-sample was analyzed using a Coulter LS 130 Laser-Sizer. The data from both fractions were then combined to give a full PSA breakdown for each sample. Following removal of inorganic matter using a sulfurous acid digest (in excess to ensure complete digestion; King et al., 1998), measurement of total particulate organic carbon and nitrogen in sediment samples was carried out using a Carlo Erba EA1108 Elemental analyzer in which dry combustion was completed at high temperature followed by separation and detection of the gaseous products.

\section{Statistical Analyses}

Data on sediment $\mathrm{C}_{\text {org }}$ content, faunal abundance, the total number of taxa, Pielou's evenness ( $\left.J^{\prime}\right)$, Shannon-Weiner diversity ( $H$ ', base: $\log 2$ ), and wet biomass in the different treatments through time were analyzed using a two-way repeated measures ANOVA with sampling block as a subject (random) factor. Data were tested for normality, heteroscedascity, and automatically checked for sphericity. Independent $t$-tests were used to compare the means of the aforementioned univariate metrics in the SC and PC plots at 365 days. Differences in macrofaunal community structure between the tailings treatments and the SC and PC plots were analyzed by non-metric multi-dimensional scaling (nMDS) based on Bray-Curtis similarities on untransformed data. To test whether the differences seen in this nMDS were due to compositional patterns, a further nMDS was produced based on presence/absence data. Due to the low number of replicates sampled in each treatment at each time point $(n=3)$, a two-way crossed analysis of similarities (ANOSIM) test was performed to test for block effects. The absence of block effects and the low number of replicates meant that a twoway ANOSIM was then used to check for significant effects of $\mathrm{C}_{\text {org }}$ and time on macrofaunal community structure (Clarke and Gorley, 2015). We used Distance based linear modeling (DISTL-M) to test for the effects of $\mathrm{C}_{\text {org }}$ and redox conditions (at 1, 2, $4 \mathrm{~cm}$ ) on untransformed macrofaunal community composition data through time. The most appropriate model to use for DISTL-M analysis was assessed by plotting the Aikake Information Criterion (AIC) and Bayesian Information Criterion (BIC) scores on a scatter plot and selecting the model with the lowest AIC and BIC scores. A distance-based redundancy analysis (dbRDA) plot was used to graphically visualize the fit of the DISTL-M model. Due to the availability of additional environmental data at 365 days, the effects of $\mathrm{C}_{\mathrm{org}}$, $\mathrm{TN}$, sediment $\mathrm{C}: \mathrm{N}$ (the ratio of sediment $\mathrm{C}_{\text {org }}$ and nitrogen), sediment grain size (median Phi) and redox potential on untransformed macrofaunal community composition data was also carried out using DISTL$\mathrm{M}$ and dbRDA analysis as described above. An alpha level of $5 \%$ was used as the criterion for statistical significance. All data were analyzed using Sigmaplot (Systat) and Primer v7 (Primer-e; Clarke and Gorley, 2015) software.

\section{RESULTS}

\section{Sediment Chemistry and Redox Conditions}

Mean $\mathrm{C}_{\text {org }}$ concentrations in the $0,0.5,1,2.5$, and $5 \%$ treatments at the start of the experiment were $0.0 \% \pm 0.0$ (range, $n=2$ ), $0.5 \% \pm 0.1(\mathrm{SE}, n=3), 1 \% \pm 0.1(\mathrm{SE}, n=3), 2.6 \% \pm 0.0$ (SE, $n=3$ ), and $4.7 \% \pm 0.0 \mathrm{C}_{\text {org }}$ (range, $n=2$ ), indicating that the sediment treatments were accurately established. Average TN content of the tailings sediments at the start of the experiment was $0.03 \% \pm 0.0$ (range, $n=2), 0.02 \% \pm 0.01(\mathrm{SE}, n=3), 0.08 \% \pm 0.01$ (SE, $n=3), 0.30 \% \pm 0.0(\mathrm{SE}, n=3)$ and $0.57 \% \pm 0.0$ (range, $n=2)$ in the $0,0.5,1,2.5$, and $5 \%$ plots. The $\mathrm{C}_{\text {org }}$ and $\mathrm{TN}$ content in the SC plots between 45 and 365 days averaged $1.6 \% \pm 0.0$ (SE, $n=12$ ) and $0.19 \% \pm 0.01$ (SE, $n=12$ ), respectively.

During the 365 day study, a significant interaction effect was detected between the factors $\mathrm{C}_{\text {org }}$ and time (two-way repeated measures ANOVA, $p=0.005)$. $C_{\text {org }}$ content in the SC plots was significantly higher than the $\mathrm{C}_{\text {org }}$ content in the $0,0.5$, and $1 \%$ treatments at all sampling points, and despite $\mathrm{C}_{\text {org }}$ content increasing in the 0 and $0.5 \%$ treatments over time, which was possibly due to greater organic $\mathrm{C}$ deposition rates from the adjacent mudflat compared to the rate of mineralization, there were no significant changes in $\mathrm{C}_{\text {org }}$ content in these, nor in the $1 \%$ treatment during the experiment (Figure 3). No significant difference in $\mathrm{C}_{\text {org }}$ content was observed between the SC plots and the $2.5 \% \mathrm{C}_{\text {org }}$ treatments at 45,115 , and 365 days, nor between the $5 \% \mathrm{C}_{\text {org }}$ plots at 115,180 , and 365 days (Figure 3 ). There was a statistically significant decrease in $\mathrm{C}_{\text {org }}$ content in the $2.5 \%$ treatment between 45 and 180 days compared to the SC plots, as well as in the $5 \%$ treatment between 45 days and later sampling times (Figure 3) possibly due to C-remineralization rates being higher than $\mathrm{C}$-deposition rates.

It was not possible to test for significant changes in TN in the different treatments at each time point through the experiment since the TN content of some sediments was below the limits of detection. However, mean TN content measured at 365 days was $0.05 \% \pm 0.01(\mathrm{SE}, n=3), 0.18 \% \pm 0.10(\mathrm{SE}, n=3), 0.11 \% \pm 0.03$ $(\mathrm{SE}, n=3), 0.16 \% \pm 0.02(\mathrm{SE}, n=3)$, and $0.21 \% \pm 0.02(\mathrm{SE}, n=3)$ in the $0,0.5,1,2.5$, and $5 \%$ plots, respectively, which indicate a slight, albeit non-significant increase in TN in the $0,0.5$, and $1 \%$ plots (Paired $t$-tests, $p>0.05$ ). Paired $t$-tests on TN data from the $2.5 \%(p=0.003)$ and $5 \%(p=0.0006) \mathrm{C}_{\text {org }}$ treatments showed a significant decrease in TN concentration between 0 and 365 days.

The SC treatments were characterized by more oxidizing conditions in the upper-sediment layers and, in general, average redox potentials decreased with increasing sediment depth (Figure 4). This was also observed in the PC plots at 365 days (Figure 4). There was a general relationship between $\mathrm{C}_{\text {org }}$ and redox potential in the tailings treatments up to 180 days. For example, tailings in the $0 \%$ plots were more oxidizing throughout the upper $4 \mathrm{~cm}$ of sediment, although they were more reducing toward the end of the experiment (i.e., at 180 and 365 days, Figure 4). In contrast, sediments in the 2.5 and $5 \% \mathrm{C}_{\text {org }}$ plots were highly reducing in the tailings throughout the experimental period (Figure 4), and for the 0.5 and $1 \%$ during the first three 

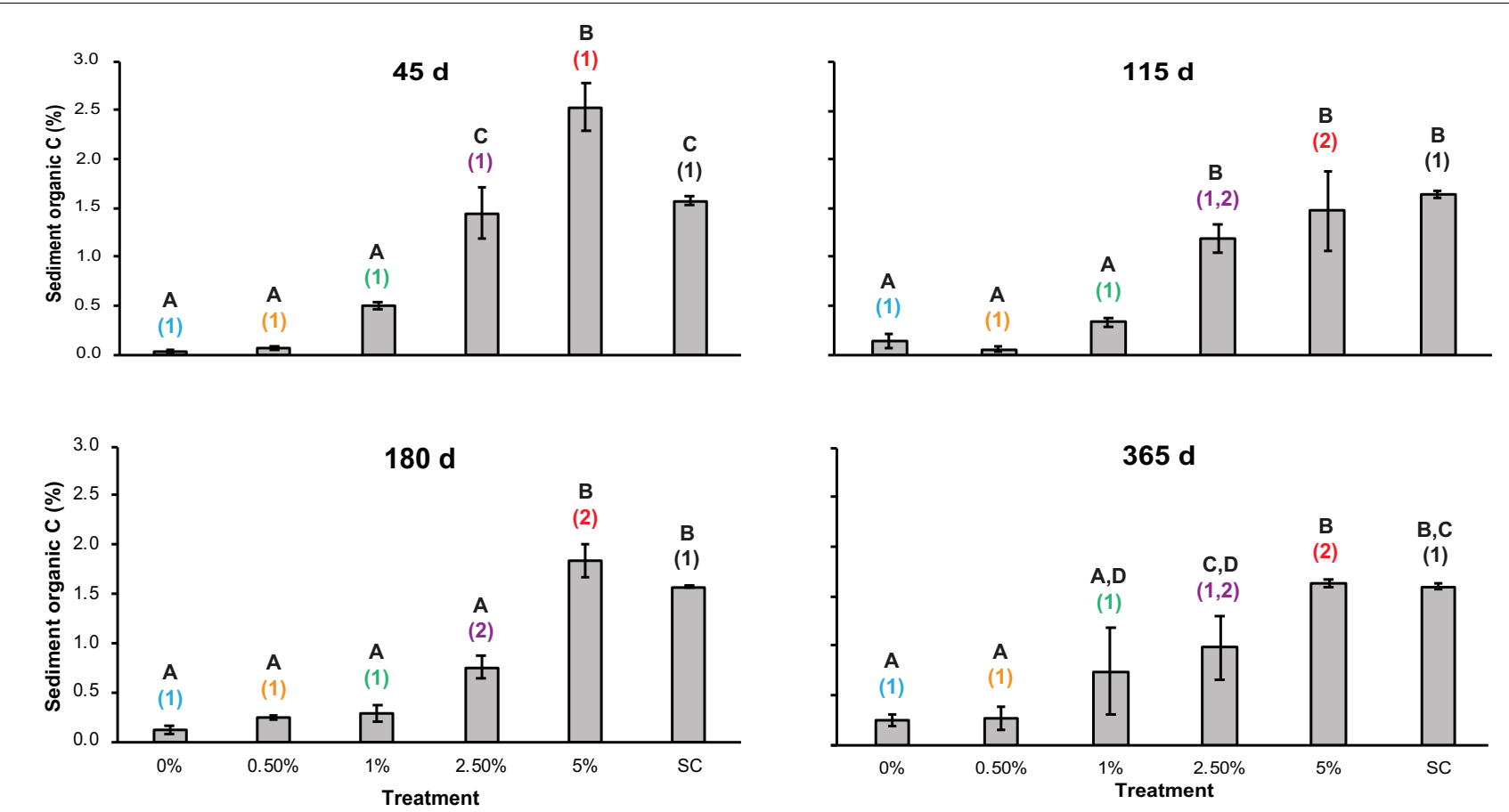

FIGURE 3 | Mean sediment organic $\mathrm{C}\left(\mathrm{C}_{\text {org }}\right)$ content $(\%)$ in the different treatments over time. Errors bars denote \pm 1 standard error of the mean $(n=3)$. Different letters denote significant differences $(p<0.05)$ between the means of the treatments at each sampling point. Different colored numbers denote significant differences $(p<0.05)$ between the means of a specific treatment at different sampling times. Colors used for the different treatments are the same as in Figure 2 to aid clarity.
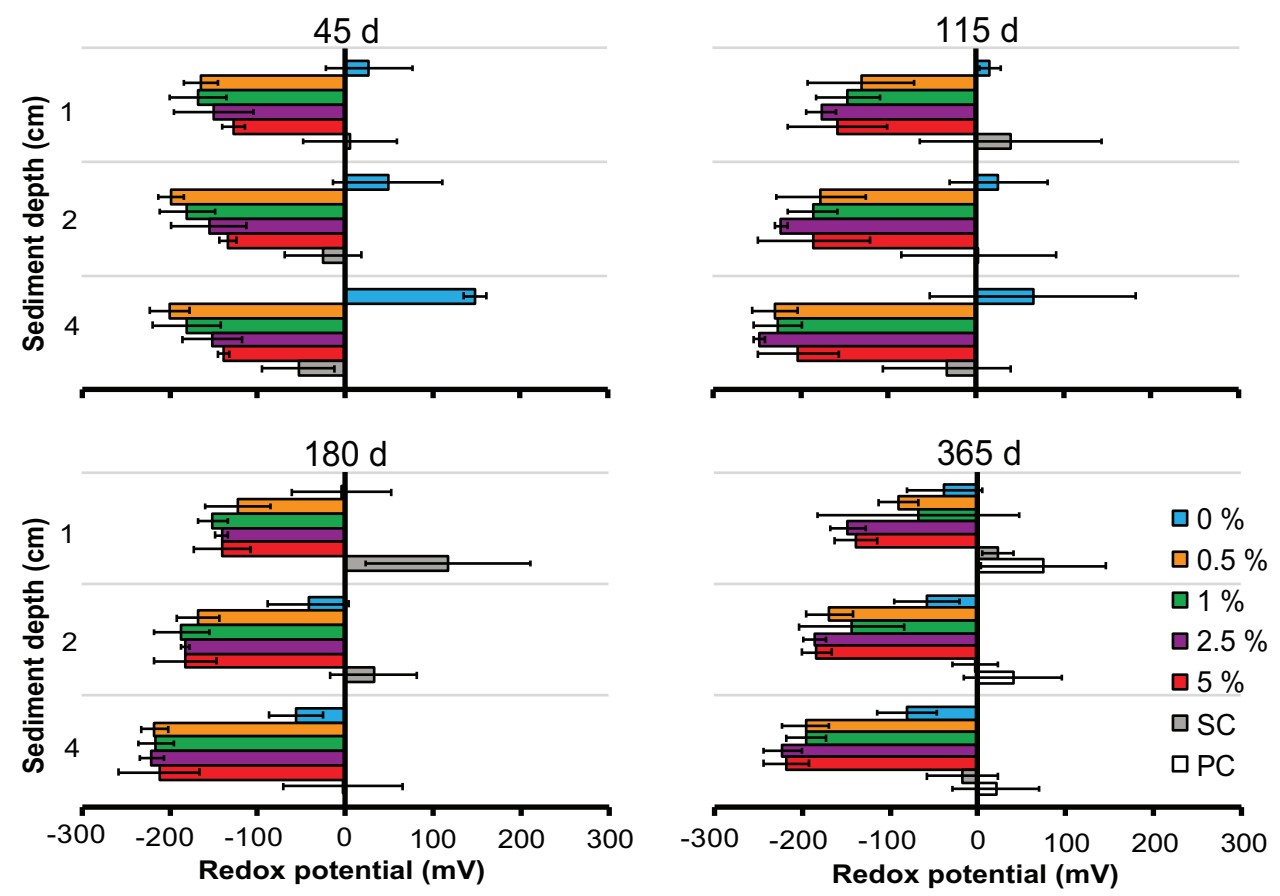

FIGURE 4 | Sediment redox potential $(\mathrm{mV})$ in the different treatments over time. Errors bars denote \pm 1 standard error of the mean $(n=3)$. Colors used for the different treatments are the same as in Figure $\mathbf{2}$ to aid clarity. 
TABLE 1 | Results from two-way repeated measures ANOVA on univariate indices.

\begin{tabular}{|c|c|c|c|c|c|}
\hline Source & DF & sS & MS & $\boldsymbol{F}$ & p-value \\
\hline \multicolumn{6}{|l|}{ (a) Macrofauna abundance } \\
\hline Treatment & 5 & 1787464190.616 & 357492838.123 & 57.511 & $<0.001$ \\
\hline Block (subject) & 2 & 4281608.059 & 2140804.029 & & \\
\hline Time & 3 & 160400890.298 & 53466963.433 & 9.589 & 0.010 \\
\hline Treatment × block (subject) & 10 & 62160771.351 & 6216077.135 & & \\
\hline Treatment $\times$ time & 15 & 223236235.499 & 14882415.700 & 2.138 & 0.037 \\
\hline \multicolumn{6}{|l|}{ (b) Number of taxa } \\
\hline Treatment & 5 & 591.625 & 118.325 & 22.325 & $<0.001$ \\
\hline Block (subject) & 2 & 7.000 & 3.500 & & \\
\hline Time & 3 & 175.819 & 58.606 & 39.559 & $<0.001$ \\
\hline Treatment $\times$ block (subject) & 10 & 53.000 & 5.300 & & \\
\hline Treatment $\times$ time & 15 & 143.431 & 9.562 & 2.369 & 0.022 \\
\hline \multicolumn{6}{|l|}{ (c) Evenness (J') } \\
\hline Treatment & 5 & 0.153 & 0.0307 & 1.520 & 0.263 \\
\hline Block (subject) & 2 & 0.090 & 0.045 & 1.913 & 0.254 \\
\hline Time & 3 & 0.048 & 0.016 & 0.684 & 0.590 \\
\hline Treatment $\times$ block (subject) & 10 & 0.202 & 0.020 & & \\
\hline Treatment $\times$ time & 15 & 0.272 & 0.018 & 0.891 & 0.584 \\
\hline \multicolumn{6}{|l|}{ (d) Shannon-Weiner $\left(H^{\prime}\right)$} \\
\hline Treatment & 5 & 18.568 & 3.714 & 8.937 & 0.002 \\
\hline Block (subject) & 2 & 0.495 & 0.247 & 0.710 & 0.544 \\
\hline Time & 3 & 8.541 & 2.847 & 10.241 & 0.009 \\
\hline Treatment $\times$ block (subject) & 10 & 4.170 & 0.417 & & \\
\hline Treatment $\times$ time & 15 & 9.434 & 0.629 & 1.822 & 0.087 \\
\hline \multicolumn{6}{|l|}{ (e) Macrofauna biomass } \\
\hline Treatment & 5 & 3828.907 & 765.781 & 24.334 & $<0.001$ \\
\hline Block (subject) & 2 & 72.858 & 36.429 & 1.143 & 0.402 \\
\hline Time & 3 & 391.550 & 130.517 & 4.803 & 0.044 \\
\hline Treatment $\times$ block (subject) & 10 & 316.195 & 31.620 & & \\
\hline Treatment $\mathrm{x}$ time & 15 & 1220.290 & 81.353 & 3.027 & 0.006 \\
\hline
\end{tabular}

Bold results denote significant results $(p<0.05)$.

sampling periods only $(45,115$, and 180 days). Mean redox potentials in the 0.5 and $1 \%$ plots were less negative at $1 \mathrm{~cm}$ depth after 365 days, although there was more variability in redox potential at $1 \mathrm{~cm}$ depth in the $1 \%$ plots at 365 days (Figure 4).

\section{Macrofauna Biodiversity}

A two-way repeated measures ANOVA found a statistically significant interaction effect of time and $\mathrm{C}_{\text {org }}$ on macrofauna abundance per core $(p=0.037)$ (Table 1 and Figure 5). Mean macrofaunal abundance in the sampling control (SC) plots averaged between $13,751 \pm 764$ SE (180 days) and 17,104 \pm 765 individuals $\mathrm{m}^{-2}$ (365 days) throughout the experimental period and was significantly higher than the mean faunal abundance in the other treatments after 45 days (Figure 5). However, no difference was detected in macrofaunal density between the tailings treatments at this time (Table 1 and Figure 5). The pattern of significantly higher macrofaunal abundances in the SC plots relative to the $1,2.5$, and $5 \% \mathrm{C}_{\text {org }}$ treatments continued throughout the experiment (Figure 5). In contrast, macrofaunal abundance increased in the $0.5 \% \mathrm{C}_{\text {org }}$ treatments at 115 and 180 days resulting in no significant difference in mean macrofauna abundance relative to the SC plots (Figure 5). Mean macrofaunal densities in the 0 and $0.5 \%$ plots at 115 days were significantly greater than those in the $1,2.5$, and $5 \% \mathrm{C}_{\text {org }}$ treatments (Figure 5). Higher mean macrofaunal abundance was also observed in the $0.5 \%$ treatment relative to the 2.5 and $5 \%$ $\mathrm{C}_{\text {org }}$ treatments at 180 days. Mean faunal abundance in the $0 \%$ treatment was significantly greater than in the 1 and $5 \% \mathrm{C}_{\text {org }}$ treatments at the end of the experiment; this was not the case for the $0.5 \% \mathrm{C}_{\text {org }}$ treatment (Figure 5). Macrofaunal abundances in the SC plots were significantly greater than in all the tailings treatments at 365 days (Figure 5). No significant difference was detected between fauna abundance in the SC and PC samples collected at 365 days ( $t$-test, $p=0.605$ ) confirming that the sampling procedure had no significant effect on this macrofaunal community structure metric.

There was a statistically significant interaction effect (twoway repeated measures ANOVA, $p=0.022$ ) between the total number of taxa found in the sediments and $\mathrm{C}_{\text {org }}$ content and time (Table 1 and Figure 6). No significant change in the number of macrofaunal taxa was observed in the SC treatment over time, 

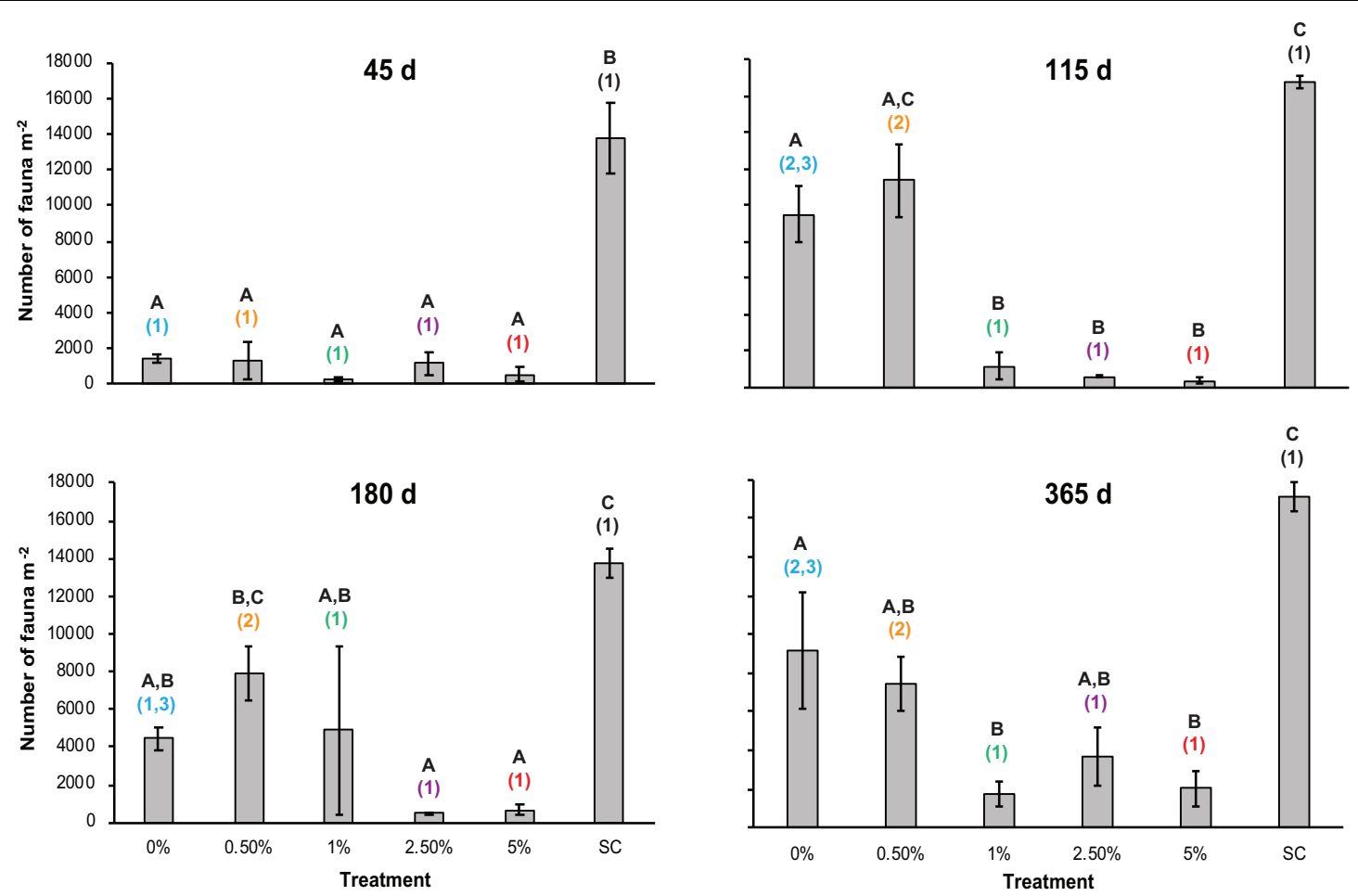

FIGURE 5 | Mean macrofaunal abundance (per $\left.\mathrm{m}^{2}\right)$ in the different treatments over time. Errors bars denote \pm 1 standard error of the mean $(n=3)$. Different letters denote significant differences $(p<0.05)$ between the means of the treatments at each sampling point. Different colored numbers denote significant differences $(p<0.05)$ between the means of a specific treatment at different sampling times. Colors used for the different treatments are the same as used in Figure 2 to aid clarity.

which suggested no significant seasonality effect on this metric (Figure 6). The number of macrofaunal taxa in the SC treatment was significantly higher than all other treatments after 45 days, but no significant difference was seen in the tailings treatments at this time (Figure 6). After $115 \mathrm{~d}$, significant differences were still detected between the SC plots and the 1, 2.5, and 5\% $\mathrm{C}_{\text {org }}$ treatments, but not the 0 or $0.5 \%$ plots (Figure 6). Moreover, mean macrofaunal richness was significantly greater in the $0 \%$ plots relative to the $1,2.5$, and $5 \% \mathrm{C}_{\text {org }}$ plots, and in the $0.5 \%$ relative to the 2.5 and $5 \% \mathrm{C}_{\text {org }}$ treatments (Figure 6). The mean number of taxa was significantly higher in the SC, 0 and $0.5 \%$ treatments compared to the $1,2.5$, and $5 \%$ plots after 180 days (Figure 6), while at the end of the experiment, significant differences were only detected between the SC and $1 \%$, SC and 5\%, and $0 \%$ and 5\% plots (Figure 6). No significant difference was detected between the mean number of taxa in the SC and PC samples collected at 365 days ( $t$-test, $p=0.643$ ), which also confirmed that the sampling regime did not significantly affect this metric.

A significant effect of time $(p=0.009)$ and $C_{\text {org }}$ content $(p=0.002)$ was found for mean Shannon-Weiner diversity $\left(H^{\prime}\right)$, though no significant interaction effect was evident $(p=0.087)$ (Table 1). Significantly higher mean $H^{\prime}$ values were found at 365 days compared to all other times, and in the SC plots versus the 1 and $5 \% \mathrm{C}_{\text {org }}$ treatments (Supplementary Figure 1). Significantly higher mean $H^{\prime}$ values were also found in the $0 \%$ compared to the $5 \% \mathrm{C}_{\text {org }}$ treatment (Table 1 and Supplementary Figure 1). As with macrofaunal abundance and the number of taxa, no significant difference between $H^{\prime}$ in the SC and PC plots at 365 days was observed ( $t$-test, $p=0.428$ ). For Pielou's evenness $(J)$, no significant effect of time, $\mathrm{C}_{\text {org }}$ nor any interaction effect was detected (Table 1 and Supplementary Figure 2), and no difference was found between mean $J$ 'values between the SC and PC plots at 365 days ( $t$-test, $p=0.476$ ).

When the top ten most abundant taxa (i.e., those taxa which contributed $85-95 \%$ of the total abundance) were analyzed, the macrofaunal community of the SC treatment was mainly dominated by the gastropod Peringia ulvae (806 \pm 220 to $1,443 \pm 711$ indiv. $\mathrm{m}^{-2}$, mean $\pm 95 \%$ confidence intervals, $n=3)$, the polychaetes Streblospio shrubsolii $(1,867 \pm 506$ to $3,947 \pm 2,237$ indiv. $\left.\mathrm{m}^{-2}\right)$ and Tharyx spp. (1,231 \pm 220 to $2,844 \pm 1,945$ indiv. $\mathrm{m}^{-2}$ ), the oligochaete Tubificoides benedii $\left(1,698 \pm 440\right.$ to $6,027 \pm 1,291$ indiv. $\left.\mathrm{m}^{-2}\right)$ and ostracods $\left(1,910 \pm 876\right.$ to $3,777 \pm 1,801$ indiv. $\left.\mathrm{m}^{-2}\right)$ (Figure 7$)$. The abundance of these taxa was lower in most mine tailings treatments compared to the SC treatment, with the exceptions of $P$. ulvae in the $0 \%(115,180$, and 365 days $)$ and $0.5 \%$ treatments (115 and 180 days), S. shrubsolii in the $0 \%$ (115 and 365 days) and $0.5 \%$ treatment (180 days), and ostracods in the $2.5 \%$ treatment (45 days) (Figure 7). Tharyx spp. polychaetes were significantly more abundant in the SC plots than all tailings treatments at 45, 115, and $180 \mathrm{~d}$ (Figure 7). At 365 days, 

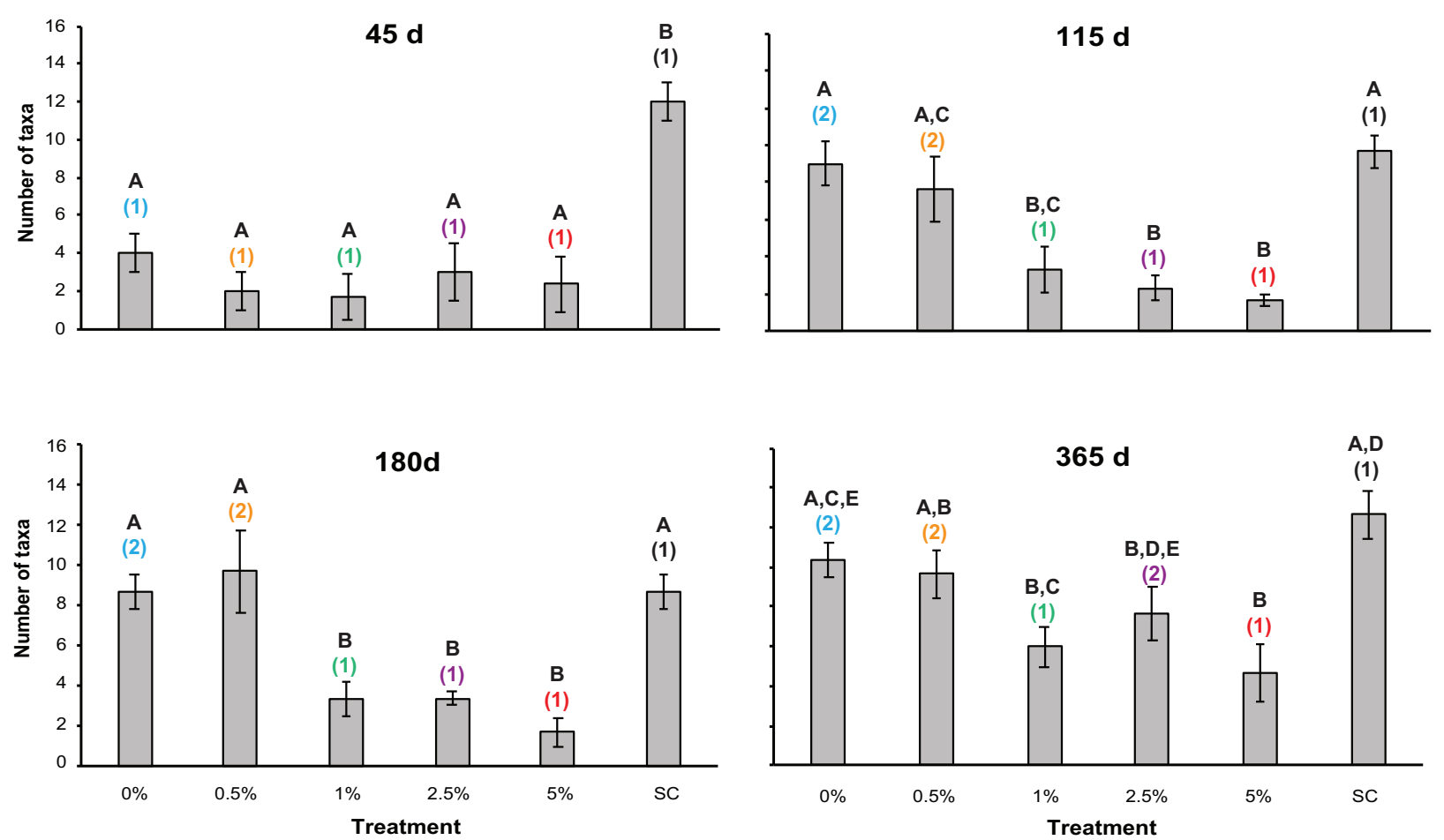

FIGURE 6 | Mean number of taxa (per $0.008 \mathrm{~m}^{2}$ core) in the different treatments over time. Errors bars denote \pm 1 standard error of the mean $(n=3)$. Different letters denote significant differences $(p<0.05)$ between the means of the treatments at each sampling point. Different colored numbers denote significant differences $(p<0.05)$ between the means of a specific treatment at different sampling times. Colors used for the different treatments are the same as used in Figure 2 to aid clarity.

the abundance of this polychaete genus in the $0 \%$ treatment was, however, statistically indistinguishable to that of the SC treatment (Figure 7). The abundance of other macrofauna (e.g., nematodes) increased over time in the 0 and $0.5 \% \mathrm{C}_{\text {org }}$ treatments (Figure 7).

\section{nMDS, DISTL-M, and dbRDA Analyses}

The nMDS on average untransformed abundance data revealed that the community composition in the SC treatments did not change significantly throughout the experiment. The community in the PC plots at 365 days was similar to that sampled in the SC treatments, again, confirming that the sampling had no marked effect on macrofaunal assemblage structure over the course of the experiment (Figure 8). The macrofaunal community in all the tailings treatments showed the greatest dissimilarity to the SC treatments at 45 days (Figure 8). Over the course of the experiment the macrofaunal community in the $0,1,2.5$, and $5 \% \mathrm{C}_{\text {org }}$ treatments progressed toward that in the SC plots as shown by the trajectories super-imposed on the nMDS in Figure 8, though differences remained at 365 days (Figure 8). The pattern was evident in the nMDS based on presence-absence data indicating that the patterns seen were related to species compositional changes as opposed to changes in macrofaunal abundances (Supplementary Figure 3). A two-way crossed ANOSIM test (factors: treatment and block) revealed that there were no significant block effects
(Global test: average $R=-0.103, p=0.959$, Supplementary Table 1). An ANOSIM test (factors: treatment and time) on untransformed data revealed that there was a significant treatment (Global test: average $R=0.675, p=0.001$ ) as well as time effect (Global test: average $R=0.289, p=0.001$ ) (Supplementary Table 1). Significantly different and wellseparated assemblages were detected between the SC and $0 \%$ $(R=0.833, p=0.002), 0.5 \%(R=0.874, p=0.001), 1 \%$ $(R=0.909, p=0.001), 2.5 \%(R=0.970, p=0.002)$, and $5 \% \mathrm{C}_{\text {org }}$ treatments $(R=0.788, p=0.001$ ) (Supplementary Table 1). The communities in the 0 and $0.5 \%$ treatments were also faunistically distinct from the 1, 2.5, and $5 \%$ $\mathrm{C}_{\text {org }}$ treatments (Supplementary Table 1). The relatively low R-statistic (0.305) between the 0.5 and $0 \%$ treatments suggest that while there are some structural differences, some commonality in species composition existed (Supplementary Table 1). This was also the case for the communities in the 1 and $2.5 \%(R=-0.045), 1$ and $5 \%(R=0.135)$ and 2.5 and $5 \%$ treatments $(R=0.275)$ (Supplementary Table 1). The macrofaunal communities after 45 days were significantly different to those after 180 days $(R=0.684, p=0.001)$ and 365 days $(R=0.729, p=0.001)$. Significant differences were also observed between 180 and 365 days $(R=0.599, p=0.001)$ (Supplementary Table 1).

DISTL-M analyses on untransformed abundance data (entire dataset) revealed that macrofaunal community composition in 


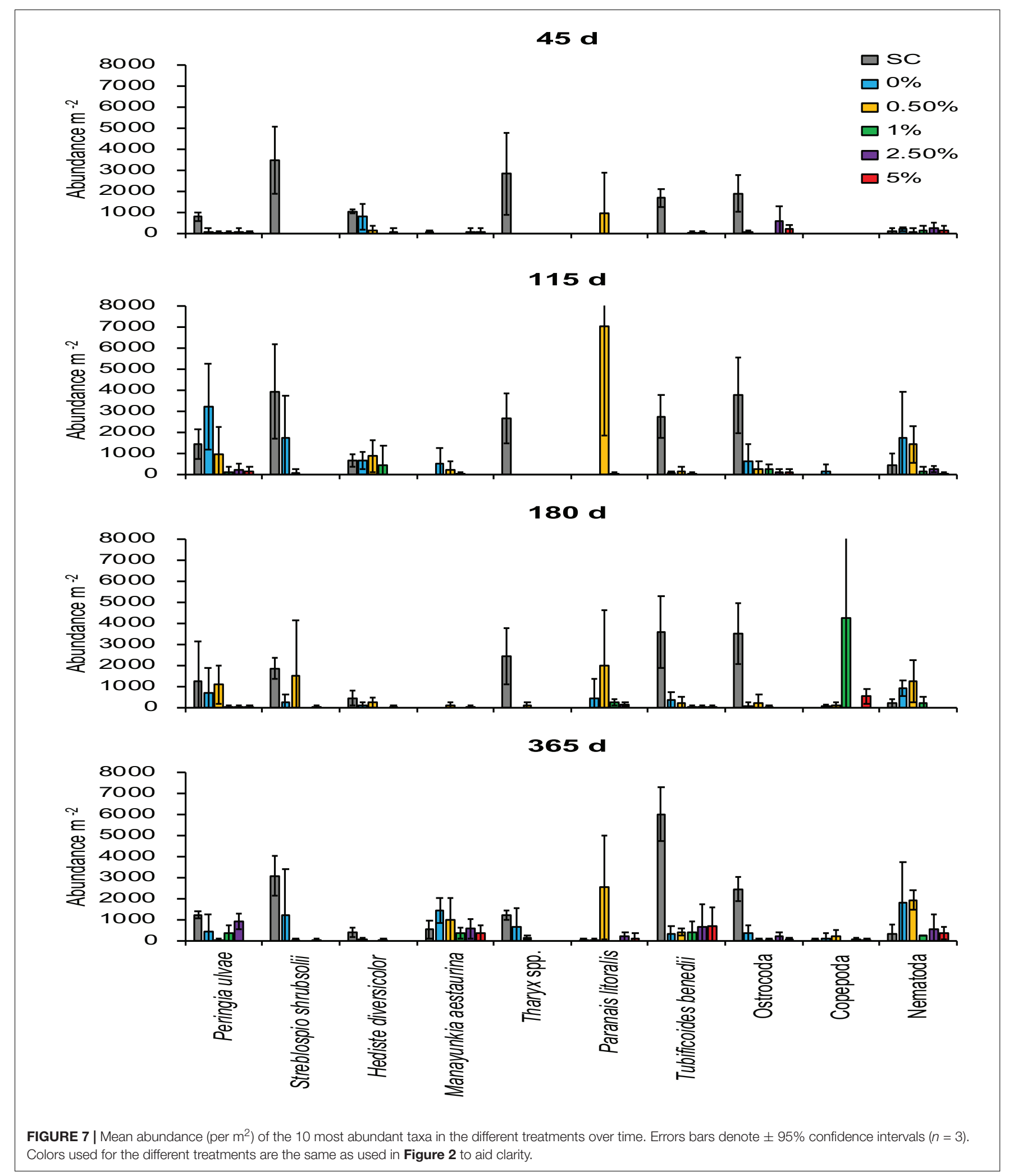

the various treatments was best explained by redox potential values $(\mathrm{mV})$ at $2 \mathrm{~cm}$ depth $\left(r^{2}=0.11, p=0.0001\right), \mathrm{C}_{\text {org }}(\%)$ $\left(r^{2}=0.06, p=0.0001\right)$, and redox values $(\mathrm{mV})$ at $4 \mathrm{~cm}$ depth $\left(r^{2}=0.04, p=0.0001\right)$. A distance-based redundancy analysis (dbRDA) plot showed points belonging to the SC, $0,0.5$, and $1 \%$ treatments widely spaced in the direction of the $2 \mathrm{~cm}$ redox 


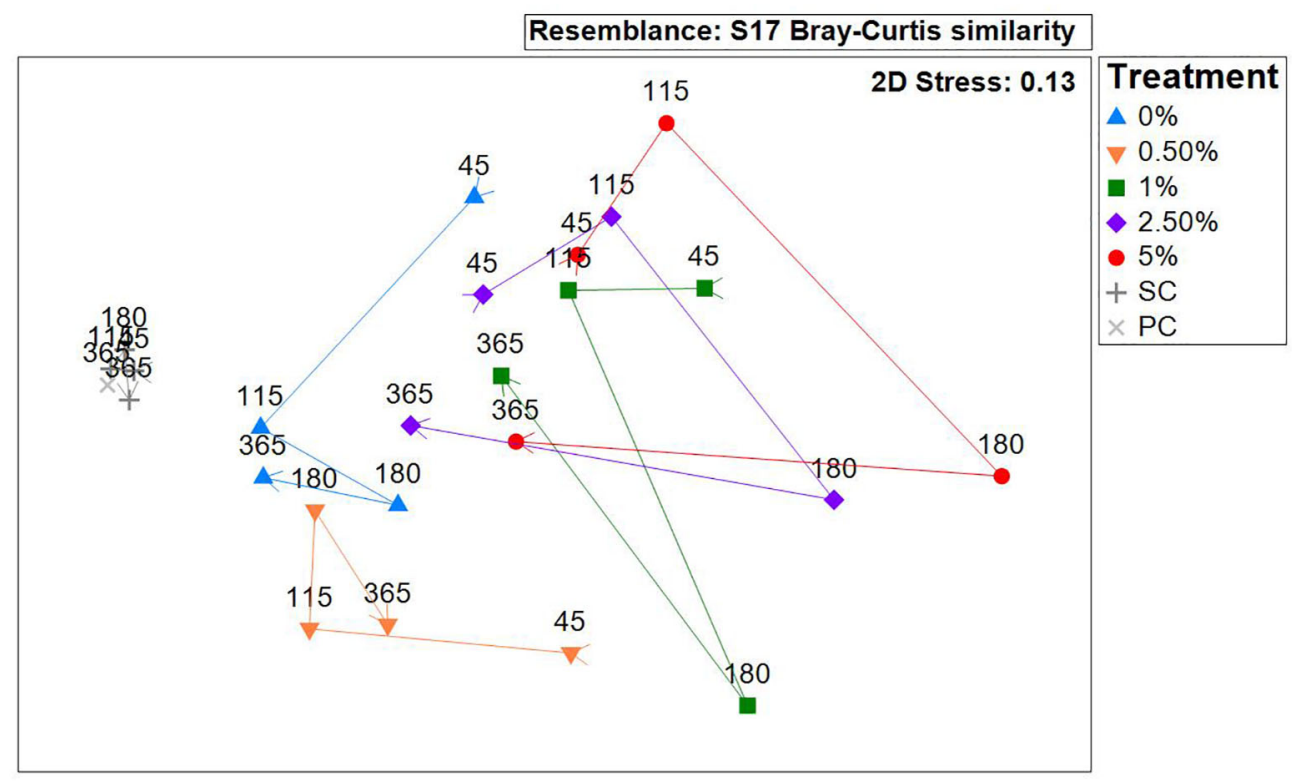

FIGURE 8 | Non-parametric multi-dimensional scaling (nMDS) ordination (based on Bray-Curtis similarity matrix on untransformed abundance data, replicates averaged for each treatment at each time point) showing temporal changes over the 365 days study period. Colored lines link each treatment and the arrows at the start and end of each line show the temporal change in macrofaunal community structure from 45 to 365 days, and how similar the communities in the different tailings treatments are relative to the communities in the background mudflat sediments (points situated closer together indicate greater similarities in community structure).

potential $(\mathrm{mV})$ vector (Figure 9; top panel), and the data points for the 2.5 and $5 \%$ treatments orientated in the direction of the $\mathrm{C}_{\text {org }}(\%)$ vector (Figure 9; top panel), showing the influence of these environmental factors on community composition in these treatments. This procedure based only on data collected at 365 days when $\mathrm{C}_{\text {org }}$, TN, C: N, redox potential and PSA data were available showed that community composition was most strongly related to $\mathrm{C}_{\text {org }}(\%)$ and sediment grain size (Figure 9; bottom panel). Median (Phi) grain size and $\mathrm{C}_{\text {org }}$ explained 23.2\% $(p=0.0008)$ and $13.1 \%$ of the variation $(p=0.009)$ in community composition, respectively. The outputs revealed that grain size had a large effect on community composition between the SC and tailings treatments, but the different community composition in the tailings treatments was driven largely by variations in $\mathrm{C}_{\mathrm{org}}$ (Figure 9). Neither TN, sediment C: N, nor redox conditions at 1 and $4 \mathrm{~cm}$ depth were significantly related to faunal community composition at $365 \mathrm{~d}$.

\section{Biomass}

We detected a significant interaction effect of $\mathrm{C}_{\text {org }}$ and time on mean macrofaunal biomass (two-way repeated measures ANOVA, $p=0.006$ ) (Table 1 and Figure 10). After 45 days, macrofaunal biomass was significantly higher in the SC plots compared to the 1, 2.5, and 5\% $\mathrm{C}_{\text {org }}$ treatments (Figure 10). At $115 \mathrm{~d}$, macrofaunal biomass in the 2.5 and $5 \% \mathrm{C}_{\text {org }}$ treatments remained significantly below that of the SC and $0 \% \mathrm{C}_{\text {org }}$ treatments (Figure 10). Significantly lower biomasses were seen in the 0,1 , and $2.5 \% \mathrm{C}_{\text {org }}$ treatments relative to the SC treatment after 180 days (N.B. the $5 \% \mathrm{C}_{\text {org }}$ treatment had only 1 sample at 180 days so no difference was detected) (Figure 10), and biomasses in all tailings treatments were significantly below that in the SC treatment at 365 days (Figure 10). Macrofaunal biomass in the SC treatments was significantly higher at 365 days compared to other sampling times, but no significant difference was detected between mean macrofaunal biomass in the SC and PC plots at 365 days ( $t$-test, $p=0.398$ ).

\section{DISCUSSION}

The disposal of mine tailings onto soft-sediment coastal ecosystems has been common practice in a variety of countries including Norway, Canada and Papua New Guinea for a number of years (Kvassnes et al., 2009; Hughes et al., 2015; Ramirez-Llodra et al., 2015). Resident benthic communities are totally smothered during this activity and the seafloor initially represents an organically sterile environment, a feature which may dramatically influence faunal colonization dynamics and ecosystem recovery (Kvassnes et al., 2009, 2011; Kvassnes and Iversen, 2013). A limited number of studies have attempted to quantify macrofaunal recovery by periodically sampling unmanipulated mine tailings discharged from nearby mines and comparing the faunal community in these sediments to that in unimpacted, soft sediment habitats (e.g., Olsgard and Hasle, 1993; Berge et al., 2011; Trannum et al., 2019). More recent studies have quantified colonization dynamics of chemically contaminated tailings (Trannum et al., 2020), though these results cannot directly be scaled up to the scale of the industry or compared with the results of this study since it used hydrodynamically 


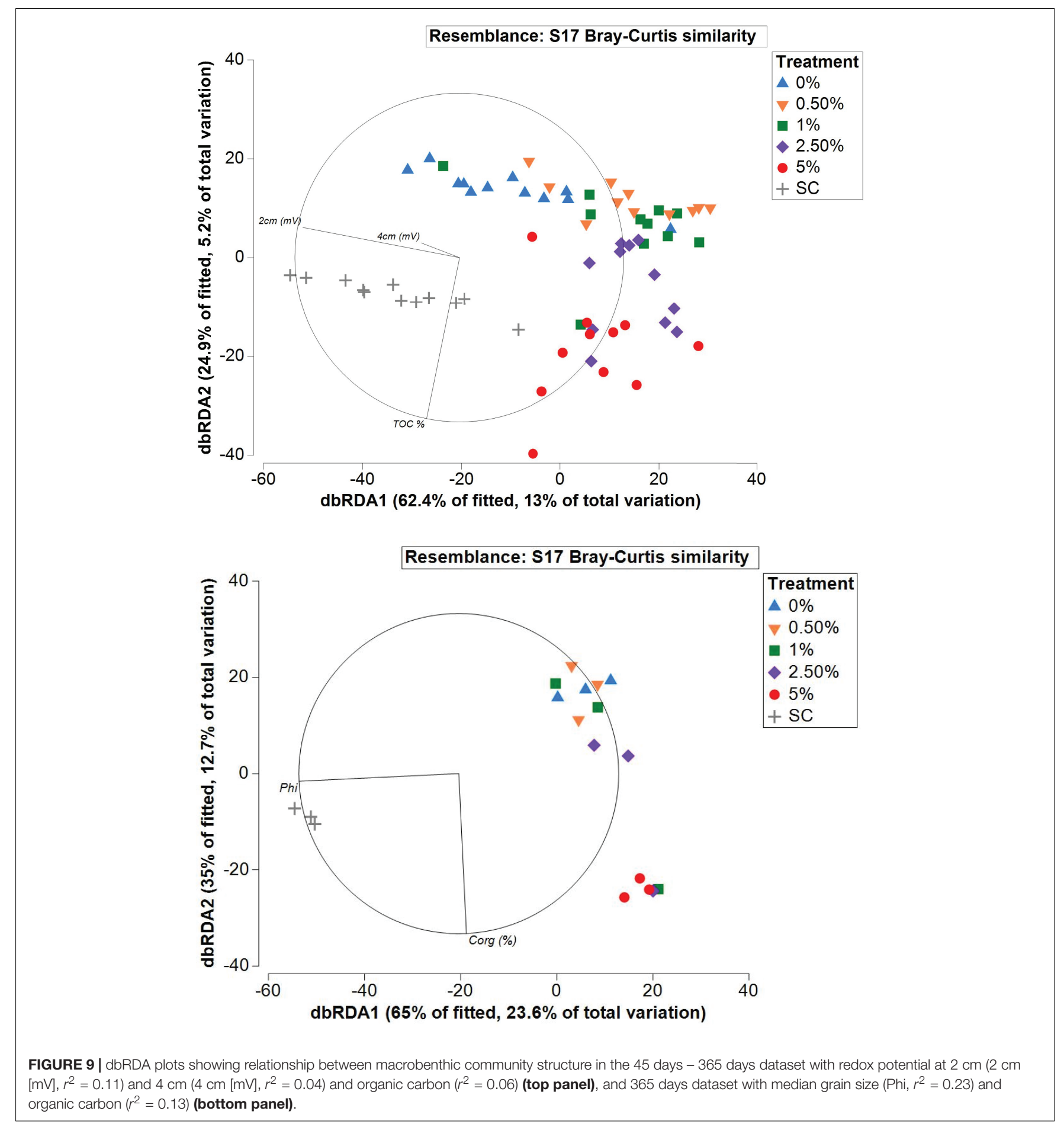

biased settlement trays that protruded above the sediment surface, which would have altered near bottom-flow and larval recruitment dynamics (Butman, 1987; Smith and Brumsickle, 1989; Snelgrove et al., 1992).

\section{Overall Findings of the Study}

We found that while there was significant temporal fluctuation in faunal abundances in the tailings plots, macrofaunal abundance, community structure and biomass in highly organically enriched tailings (e.g., $\geq 1 \% \mathrm{C}_{\text {org }}$ ) were significantly different to those in the ambient sediment after 1 year. The number of taxa and Shannon-Weiner diversity in the inert $\left(0 \% \mathrm{C}_{\text {org }}\right)$ and slightly enriched tailings treatments $\left(0.5 \% \mathrm{C}_{\text {org }}\right)$ were statistically indistinguishable to those of the SC plots after this time period. The mean number of taxa per core in the $0 \%(10 \pm 1$ taxa, $n=3$, SEM $)$ and 

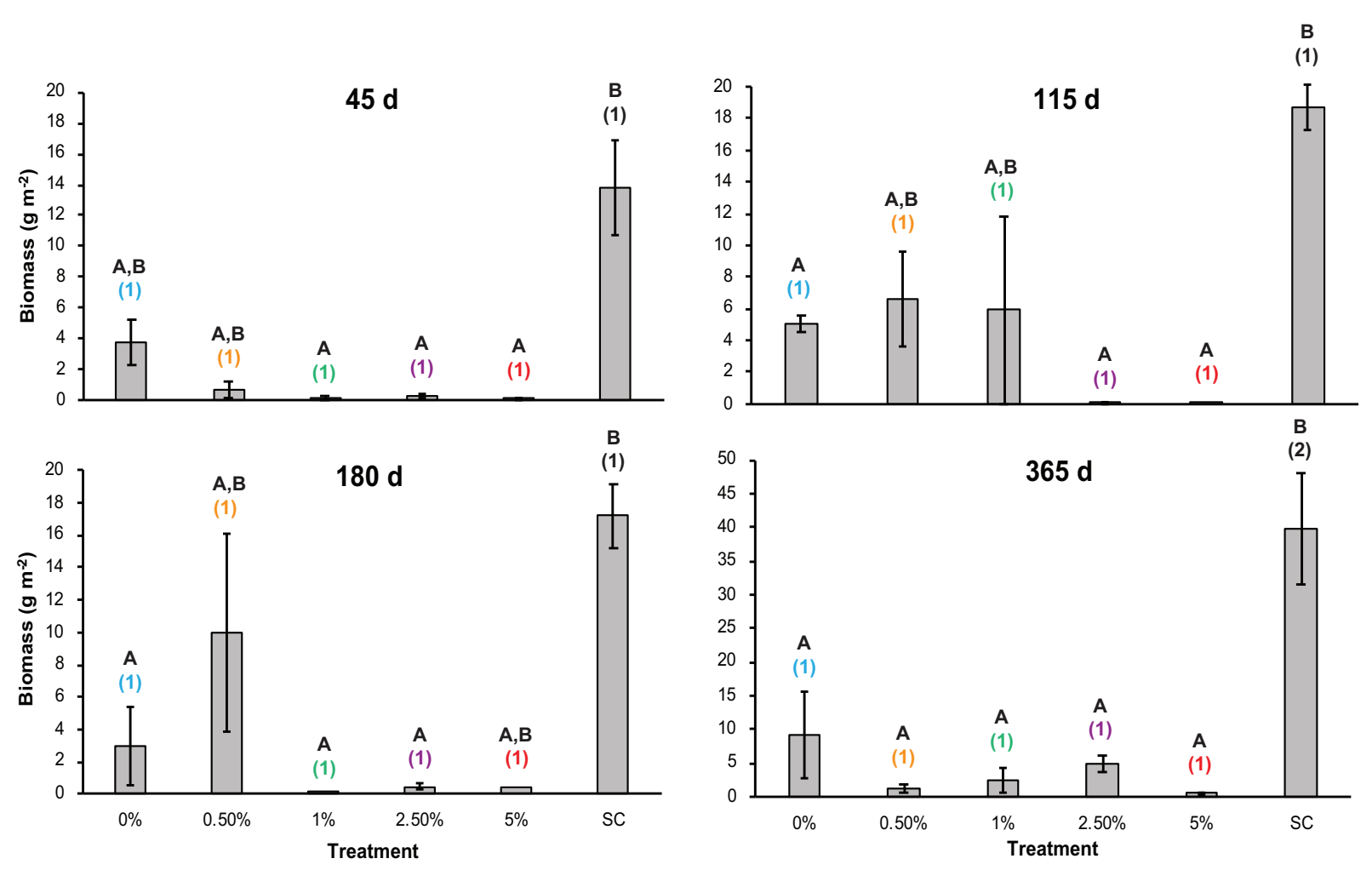

FIGURE 10 | Mean biomass ( $\mathrm{g}$ per $\mathrm{m}^{2}$ ) in the different treatments over time. Errors bars denote \pm 1 standard error of the mean $(n=3)$. Different letters denote significant differences $(p<0.05)$ between the means of the treatments at each sampling point. Different colored numbers denote significant differences $(p<0.05)$ between the means of a specific treatment at different sampling times. Colors used for the different treatments are the same as used in Figure $\mathbf{2}$ to aid clarity.

$0.5 \%$ treatments $(10 \pm 1$ taxa, $n=3$, SEM) at 365 days was also similar to that found in previously defaunated mudflat sediments that were allowed to colonize for 1 year at this experimental site (Bolam et al., 2004), suggesting partial recovery of seafloor biodiversity to the same level as the background sediments at zero and low $\mathrm{C}_{\text {org }}$ levels. However, nMDS analysis revealed that the communities in the 0 and $0.5 \%$ treatments were still distinct to those of the natural mudflat community at 365 days. Furthermore, distancebased linear modeling revealed that only $21 \%$ of the variance in macrofaunal community composition was explained by $\mathrm{C}_{\text {org }}$ and redox conditions throughout the experiment, and $36 \%$ was explained by $\mathrm{C}_{\mathrm{org}}$ and median grain size (Phi) at 365 days. These data suggest that adding little to no organic material to mine tailings, so that resulting $\mathrm{C}_{\text {org }}$ levels are $\leq 0.5 \%$, enhances the recovery of certain benthic assemblage characteristics (e.g., number of taxa), but sediment particle size, redox conditions and other untested factors play an important role in driving macrofaunal colonization dynamics of deposited mine tailings. Thus, our null hypothesis that macrofaunal abundance, community structure and biomass in tailings enriched by $<1 \% \mathrm{C}_{\text {org }}$ do not show any significant difference to those of ambient sediments in 1 year, in contrast to tailings with greater concentrations of $\mathrm{C}_{\mathrm{org}}$, is only partially supported.

\section{Limitations of the Study}

In this experimental study, we used hydrodynamically-unbiased settlement trays that were deployed flush with the surrounding sediment (i.e., there was no difference in height between the edge of the tray and surrounding sediment) to test whether macrofaunal colonization of mine tailings is enhanced through the addition of organic material, and whether the macrofauna community colonizing the tailings resembles that of background ambient sediments faster when tailings are enriched. Although the hydrodynamic bias was reduced in our experimental design by burying the trays in the sediment, a number of limitations existed with our experimental design. Firstly, although the plots were spatially separated and set up in a sheltered, low hydrodynamic environment, the deposition of organic material from the adjacent mudflat into the trays containing tailings could have altered the organic composition over time. This would potentially have affected colonization of the low $\mathrm{C}_{\text {org }}$ treatments ( 0 and $0.5 \%$ treatments) to a greater extent than the higher $\mathrm{C}_{\text {org }}$ treatments. Analysis of $\mathrm{C}_{\mathrm{org}}$ in the 0 and $0.5 \%$ tailings sediments showed a rise in $\mathrm{C}_{\text {org }}$ concentration between 45 and 365 days, however, the change was not significant (Figure 3). One might argue, however, that such increases in sediment organic carbon content through natural deposition realistically reflects the subsequent processes following large-scale mine tailings deposition. Secondly, the 
biomass of microphytobenthos was not quantified in any of the treatment plots despite microphytobenthos being an important food source to benthic meio- and macrofaunal assemblages (Middelburg et al., 2000; Evrard et al., 2010), which may have led to different colonization patterns being observed in the different treatment types. Thirdly, we used a highly labile source of $\mathrm{C}_{\text {org }}$ that could have led to slower colonization in the $>0.5 \%$ tailings treatments. However, the lack of a significant effect of sediment TN and C: $\mathrm{N}$ on macrofaunal community structure at $365 \mathrm{~d}$ suggests these effects were minimal. Finally, intertidal estuarine habitats can be significantly affected by daily changes in temperature, desiccation and salinity, which may affect colonization processes, and are not experienced as much as in subtidal habitats where most tailings disposal occurs (Ellis and Hoover, 1990; Ellis and Ellis, 1994; Kvassnes and Iversen, 2013; Ramirez-Llodra et al., 2015; Trannum et al., 2019). Thus, care should be taken when our results are used to hypothesize about the colonization rates of organically modified subtidal tailings deposits.

\section{Comparisons With Other Colonization Studies, and the Importance of Tailings Grain Size}

A previous experimental colonization study by Bolam et al. (2004) observed that defaunated mudflat sediments reached an abundance of 48,875 macrofaunal individuals $\mathrm{m}^{-2}$ in 1 year. Neira et al. (2015) sampled mean macrofaunal abundances of 16,875 animals $\mathrm{m}^{-2} 3$ months after defaunated muddy sediments were deployed subtidally in Shelter Island Yacht Basin, California. Finally, Thrush and Roper (1988) documented a median abundance of between 1,625 and 8,750 animals $\mathrm{m}^{-2}$ in defaunated mudflat sediments following a colonization period of 20 days. In this study, a maximum of 9,210 macrofaunal individuals $\mathrm{m}^{-2}\left(0 \% \mathrm{C}_{\text {org }}\right.$ treatment $)$ colonized the tailings treatments in 365 days (Figure 5), which indicated that colonization rates of our unmanipulated and organically modified tailings were generally slower compared to other studies that have examined colonization dynamics using defaunated muddy sediments. These comparisons suggest that a first-order approach whereby tailings are enriched in organic material may not directly lead to enhanced ecosystem recovery in mine tailings disposal areas. It is possible that the lower $\mathrm{C}_{\text {org }}$ content of the 0 and $0.5 \%$ tailings treatments (Figure 3) versus the ambient mudflat sediments sampled in Bolam et al. (2004; $\mathrm{C}_{\text {org }}$ content: 1.5 - 2\%) was a reason for the difference in colonization rates observed between these studies since the results from the DISTL-M that used the entire dataset did show that the SC plots and 0 and $0.5 \%$ treatments separated along the $\mathrm{C}_{\text {org }}$ vector (Figure 9). However, the DISTL-M analysis on the 365 days macrofauna dataset revealed that sediment grain size was also a major factor driving differences in macrofaunal community composition between the SC plots and tailings treatments, indicating that this could have also contributed to the slower colonization rates and reduced macrofaunal abundance in the tailings treatments at 365 days.

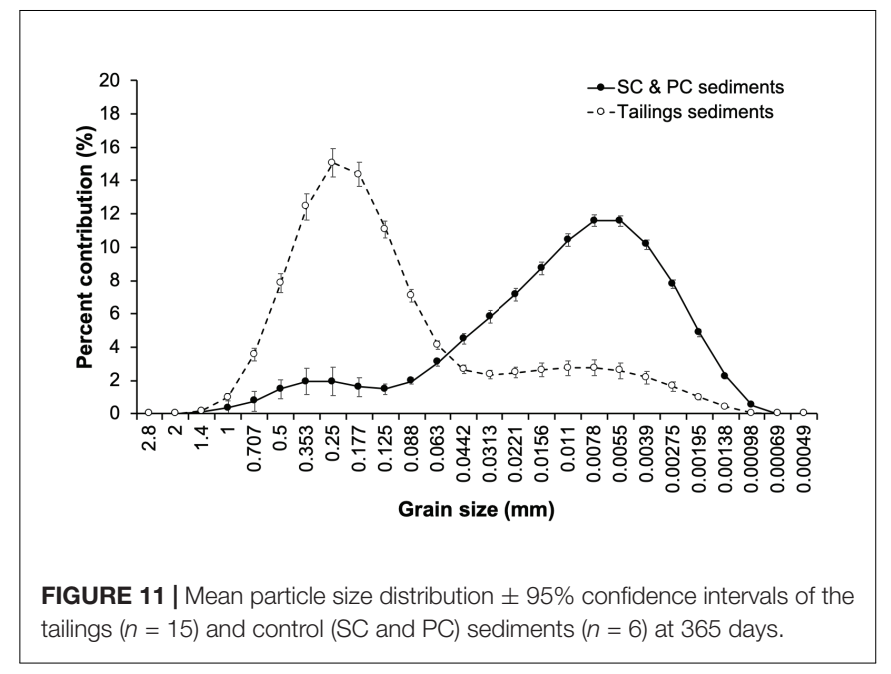

The sediment grain size of the ambient mudflat sediments (i.e., SC and PC plots) was much finer (85\% of particles were $<0.063 \mathrm{~mm})$ compared to the mine tailings used $(73 \%>0.063 \mathrm{~mm})$ (Figure 11). The smaller grain size of the defaunated sediments sampled by Bolam et al. (2004) and on the adjacent mudflat in this study may have led to greater sorption of organic matter to sediment particles (Hedges and Keil, 1995; Bergamashi et al., 1997) and less microbial degradation due to organic matter being located inside pores that were too small to allow the functioning of hydrolytic enzymes necessary for organic matter decay (Mayer, 1994). This, in turn, could have led to more oxidizing conditions in the defaunated mudflat sediments as shown by Bolam et al. (2004) allowing greater survival of colonizing fauna. In contrast, the larger grain sizes of the tailings particles possibly resulted in less organic matter binding and greater microbial degradation in our study. Greater microbial degradation may have caused a reduction in porewater oxygen and more reducing conditions in the sediments (Figure 4), which limited aerobic microbial growth and faunal colonisztion of the tailings. Smit et al. (2008) observed that the proportion of benthic communities negatively affected by alterations to sediment grainsize distributions (i.e., those communities that experience a loss in faunal abundance) increased with increased sediment particle size, with the greatest effect being observed between 0.1 and $1 \mathrm{~mm}$. More than $65 \%$ of the mine tailings particles were between 0.125 and $1 \mathrm{~mm}$ relative to approximately $9 \%$ in the ambient mudflat sediments.

Whilst redox conditions, $\mathrm{C}_{\text {org }}$ content and sediment grain size were factors displaying a significant influence on macrofaunal community composition between the ambient mudflat sediments and tailings plots (Figure 9), DISTL-M analysis indicated that $64 \%$ (365 days dataset) to $79 \%$ (entire dataset) of the variability in macrofaunal community composition was not explained by these aforementioned characteristics. Moreover, neither TN or the lability of the sediment organic matter (C: N) significantly influenced macrofaunal community composition at 365 days suggesting that they had little effect on the macrofaunal communities sampled at 45, 115, and 180 days. Although 

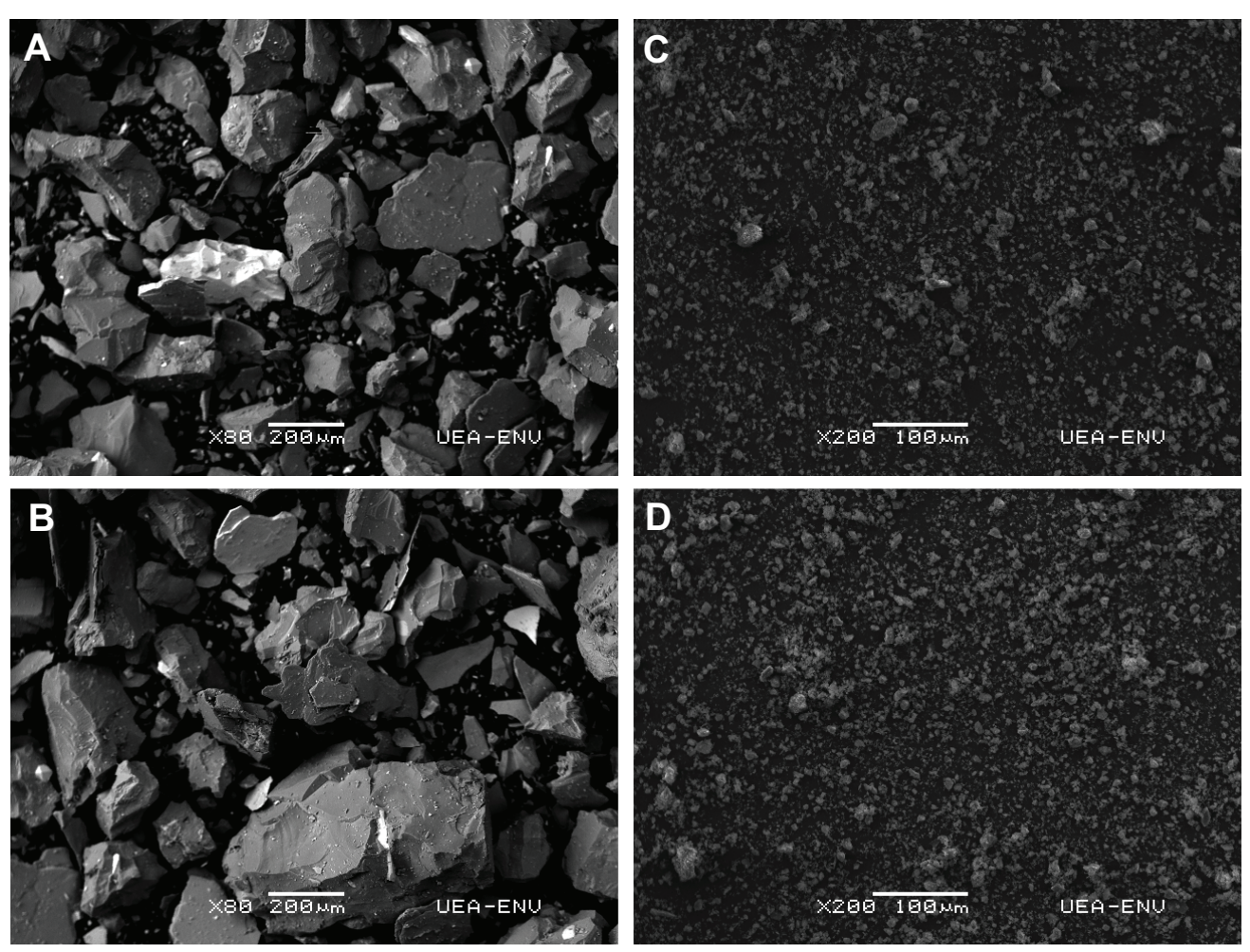

FIGURE 12 | Scanning Electron Microscope (SEM) images of the inert mine tailings ( $0 \% \mathrm{C}_{\text {org }}$ treatment) $\mathbf{( A , B )}$ and background mudflat sediments at the experimental site (C,D). Scale bars are shown in each image.

differences in microphytobenthos biomass between treatments may have been a factor, the angularity of the particles in the mine tailing sediments (Figure 12) may have also limited macrofaunal colonization and generated the differences in macrofaunal community composition compared to the adjacent mudflat. Giere (2009) suggested that particle shape is an indirect factor determining meiobenthic colonization due to its effects on sediment water content and permeability. Sediments consisting of predominately angular particles, as was the case for our mine tailings (Figure 12), would have smaller pore spaces due to tighter packaging, lower permeability and water content leading to more reducing conditions (Figure 4), and the restriction to movement would prevent large individuals from successfully colonizing. The sharp-edged characteristics of the tailings compared to the natural mudflat sediments may have created further difficulties for colonizing fauna as greater particle angularity could cause internal damage to deposit feeding animals such as cirratulid polychaetes (e.g., Tharyx spp.) and oligochaetes (Olsgard and Hasle, 1993) that were highly abundant in the SC plots but more-or-less absent in many of the tailings plots (Figure 7). The relatively greater particle angularity of the tailings could, therefore, have possibly led to a further stress on the colonizing fauna resulting in significantly lower faunal abundance, biomasses and different community structure between the SC plots and tailings treatments at 365 days, and the slower colonization rates compared to other studies (e.g., Bolam et al., 2004; Neira et al., 2015). Based on these findings, we recommend that future studies should aim to test the influence of tailings angularity and grain size on macrobenthic colonization using hydrodynamically unbiased colonization trays, or that mining companies cap tailings deposits with natural seafloor sediments to make sure that the grain size of the sediment being colonized matches that of natural seafloor sediments.

\section{The Role of Organic $\mathbf{C}$ in Tailings Colonization}

While it is clear from the DISTL-M analyses that redox conditions and sediment grain size led to different macrobenthic community composition between the SC and tailings plots and potentially played a major role in driving differences in colonization processes compared to other studies, $\mathrm{C}_{\text {org }}$ was a major factor driving differences between the $\geq 1 \%$ tailings treatments and those of lower $\mathrm{C}_{\text {org }}$ content (Figure 9). Moreover, the number of taxa in the $\geq 1 \%$ plots was significantly lower than in the SC plots after 115, 180, and 365 days (with the exception of the $2.5 \% \mathrm{C}_{\text {org }}$ plots at 365 days), which contrasted with the $\leq 0.5 \%$ treatments. Collectively, these results show that enriching tailings with organic matter to $\geq 1 \%$ can impede colonization and macrofaunal recovery to a greater extent than where little or no organic material is added (final $\mathrm{C}_{\text {org }}$ content: $\leq 0.5 \%$ ) as shown previously for organically modified marine sediments (Ford et al., 2001). While some natural intertidal and subtidal habitats (e.g., 
mangrove and saltmarsh systems) provide habitat to benthic communities that are more resilient to carbon-rich sediments (Schrijvers et al., 1995; Nagelkerken et al., 2008), meta-analyses between macrobenthic species richness and sediment organic content have shown that species richness in sediments often only remains stable up to a sediment $\mathrm{C}_{\text {org }}$ content of $1 \%$ (Hyland et al., 2005). Above this concentration, macrobenthic species richness declines as a result of a reduction of porewater oxygen and the build-up of toxic metabolic by-products (e.g., sulfide) in the sediment due to aerobic and anaerobic microbial organicmatter remineralization (Pearson and Rosenberg, 1978; Hyland et al., 2005; Kutti et al., 2007; Sweetman et al., 2014). The higher number of taxa in the $2.5 \% \mathrm{C}_{\text {org }}$ treatment at 365 days relative to 45 days was possibly related to the decrease in sediment $\mathrm{C}_{\text {org }}$ content to $\sim 1 \%$, likely caused by higher rates of organic-matter mineralization compared to the rates of $\mathrm{C}$ deposition (Figure 3 ). Although sediment $\mathrm{C}_{\text {org }}$ content decreased significantly between 45 and 365 days in the $5 \% \mathrm{C}_{\text {org }}$ treatment, it remained above $1.5 \%$ at 365 days, which likely resulted in no significant change in faunal abundance, number of taxa or biomass between 45 and 365 days in this treatment. Interestingly, the $\mathrm{C}_{\text {org }}$ content of the SC plots was approx. 1.6\% at each sampling period (Figure 3), so the higher redox potentials and high faunal abundance, number of taxa, and biomass measured in these plots cannot solely be explained on the basis of sediment $\mathrm{C}_{\text {org }}$ levels. The sedimentary carbon in the SC plots was, however, most likely a combination of refractory and labile carbon (Middelburg et al., 1996) which enhanced sedimentary $\mathrm{C}_{\text {org }}$ content above $1 \%$ but limited the development of highly reducing conditions in the sediment (Figure 3), and the significant production of toxic metabolic by-products. This was in contrast to the labile fish-farm pellets that were used to enrich the $\mathrm{C}$ content of the tailings, which together with the larger, more angular tailings particles possibly led to more highly reducing conditions that significantly affected faunal abundance, biomass and the composition of the faunal assemblage in the $\geq 1 \% \mathrm{C}_{\text {org }}$ tailings plots (Kutti et al., 2007; Bannister et al., 2014; Sweetman et al., 2014).

\section{CONCLUSION}

This experimental study has documented that macro faunal colonization of intertidal tailings can be improved by adding little or no organic material to tailings so that they contain $\leq 0.5 \%$ organic carbon. However, faunal abundance, community composition and biomass in non-enriched and organically enriched tailings still lagged behind compared to those in ambient mudflat sediments at 365 days. The colonization rates of the tailings were also found to be dependent on sediment grain size and redox conditions in addition to $\mathrm{C}_{\mathrm{org}}$, implying that mining companies disposing tailings should seek to ensure that differences in the grain size of the tailings and that of the receiving environment are reduced as far as possible, or that capping with ambient seafloor sediments takes place following tailings disposal. Our results also show that a significant proportion of the variability in macrobenthic community composition between the treatments was unexplained by the collected environmental data. Hence, we recommend that further studies test the effects of microphytobenthos biomass and particle angularity on faunal colonization of mine tailings in future. Collectively, this study highlights the complex nature of the considerations that need to be addressed by both policy makers and industries that produce tailings when the mandatory end-of-life rehabilitation procedures for STP's are designed and undertaken.

\section{DATA AVAILABILITY STATEMENT}

The raw data supporting the conclusions of this article will be made available by the authors, without undue reservation, to any qualified researcher.

\section{AUTHOR CONTRIBUTIONS}

AS, AK, and SB generated the research funding. AS and SB designed the experiments and carried out the study with $\mathrm{BH}$. $\mathrm{BH}$ sorted and identified the macrofauna. AS analyzed the data and wrote the manuscript, with contributions from all other authors. All the authors agreed to be accountable for the content of the work.

\section{FUNDING}

The work described here was funded by a Norwegian Research Council project "Improved submarine tailing placements (STPs) in Norwegian fjords" (project \#204033) awarded to AS, AK, and SB. AS was also supported during the writing of the manuscript with funding from the GCRF One Ocean Hub. The One Ocean Hub is an independent programme for collaborative research for sustainable development funded by UK Research and Innovation (UKRI) through the Global Challenges Research Fund (GCRF), GCRF is a key component in delivering the UK AID strategy and puts UK-led research at the heart of efforts to tackle the United Nations Sustainable Development Goals.

\section{ACKNOWLEDGMENTS}

We thank Trine Dale at the Norwegian Institute for Water Research (NIVA) for helping with the field work, and Rana Gruber Mineral AS for supplying the mine-tailings sediments that were used for these experiments. We would also like to thank Bertrand Lézé at the Faculty of Science, University of East Anglia, United Kingdom for undertaking the Scanning Electron Microscope (SEM) analysis on the tailings and ambient sediments.

\section{SUPPLEMENTARY MATERIAL}

The Supplementary Material for this article can be found online at: https://www.frontiersin.org/articles/10.3389/fmars.2020. 00649/full\#supplementary-material 


\section{REFERENCES}

Bannister, R. J., Valdemarsen, T., Hansen, P. K., Holmer, M., and Ervik, A. (2014). Changes in benthic sediment conditions under an Atlantic salmon farm at a deep, well flushed coastal site. Aquacul. Env. Interac. 5, 29-47. doi: 10.3354/ aei00092

Bergamashi, B. A., Tsamakis, E., Keil, R. G., Eglinton, T. I., Montluçon, D. B., and Hedges, J. I. (1997). The effect of grain size and surface area on organic matter, lignin, and carbohydrate concentration and molecular compositions in Peru margin sediments. Geochem. Cosmochim. Acta 61, 1247-1260. doi: 10.1016/s0016-7037(96)00394-8

Berge, J. A., Beylich, B., Gitmark, J. K., and Ledang, A. B. (2011). "Monitoring of the Bøkfjord, N Norway - preliminary investigation 2010," in Turbidity, Soft Bottom Fauna, Hard Bottom Organisms and the Occurrence of Acrylamid (In Norwegian), (Oslo: Norwegian Institute for Water Research).

Bolam, S. G. (2012). Impacts of dredged material disposal on macrobenthic invertebrate communities: a comparison of structural and functional (secondary production) changes at disposal sites around England and Wales. Mar. Pollut. Bull. 64, 2199-2210. doi: 10.1016/j.marpolbul.2012. 07.050

Bolam, S. G. (2014). Macrofaunal recovery following the intertidal recharge of dredged material: a comparison of structural and functional approaches. Mar. Environ. Res. 97, 15-29. doi: 10.1016/j.marenvres.2014.01.008

Bolam, S. G., Rees, H., Murray, L. A., and Waldock, R. (2003). "Intertidal Placement of Fine-Grained Dredged Material," in Proceedings of the 28th International Conference of Coastal Engineers, Cardiff, July 2002. (New York, NY: American Society of Civil Engineers), 2307-2328.

Bolam, S. G., Rees, H. L., Somerfield, P., Smith, R., Clarke, K. R., Warwick, R. M., et al. (2006). Ecological consequences of dredged material disposal in the marine environment: a holistic assessment of activities around the England and Wales coastline. Mar. Poll. Bull. 52, 415-426. doi: 10.1016/j.marpolbul.2005.09. 028

Bolam, S. G., Whomersley, P., and Schratzberger, M. (2004). Macrofaunal recolonization on intertidal mudflats: effect of sediment organic and sand content. J. Exp. Mar. Biol. Ecol. 306, 157-180. doi: 10.1016/j.jembe.2004.01.007

Burd, B. J. (2002). Evaluation of mine tailings effects on a benthic marine infaunal community over 29 years. Mar. Environ. Res. 53, 481-519. doi: 10.1016/S01411136(02)00092-2

Butman, C. A. (1987). Larval settlement of soft-sediment invertebrates: the spatial scales of pattern explained by active habitat settlement and the emerging role of hydrodynamical processes. Oceanogr. Mar. Biol. Annu. Rev. 25, 113-165.

Clarke, K. R., and Gorley, R. N. (2015). PRIMER v7: User Manual/Tutorial. Plymouth: PRIMER-E.

Ellis, D., and Ellis, K. (1994). Very deep STD. Mar. Pollut. Bull. 28, 472-476. doi: 10.1016/0025-326x(94)90519-3

Ellis, D. V., and Hoover, P. M. (1990). Benthos in tailings beds from an abandoned coastal mine. Mar. Pollut. Bull. 21, 477-488.

Evans, P. R., Ward, R. M., Bone, M., and Leakey, M. (1998). Creation of temperateclimate intertidal mudflats: factors affecting colonisation and use by benthic invertebrates and their bird predators. Mar. Pollut. Bull. 37, 535-545. doi: 10.1016/s0025-326x(98)00140-4

Evrard, V., Soetaert, K., Heip, C. H. R., Huettel, M., Xenopoulos, M. A., and Middelburg, J. J. (2010). Carbon and nitrogen flows through the benthic food web of a photic subtidal sandy sediment. Mar. Ecol. Prog. Ser. 416, 1-16. doi: 10.3354/meps08770

Ford, R. B., Thrush, S. F., and Probert, P. K. (2001). The interacting effect of hydrodynamics and organic matter on colonization: a soft-sediment example. Est. Coast. Shelf Sci. 52, 705-714. doi: 10.1006/ecss.2001.0784

Giere, O. (2009). Meiobenthology - The Microscopic Motile Fauna of Aquatic Sediments, 2nd Edn. Berlin: Springer.

Green Book (2012). The Clean Seas Environment Monitoring Programme (CSEMP) Green Book. Lowestoft: Cefas, 8.

Hedges, J. I., and Keil, R. G. (1995). Sedimentary organic carbon preservation: an assessment and speculative synthesis. Mar. Chem. 49, 81-115. doi: 10.1016/ 0304-4203(95)00008-f

Hughes, D. J., Shimmield, T. M., Black, K. D., and Howe, J. A. (2015). Ecological impacts of large-scale disposal of mining waste in the deep sea. Sci. Rep. 5:9985.
Hyland, J., Balthis, L., Karakassis, I., Magni, P., Petrov, A., Shine, J., et al. (2005). Organic carbon content of sediments as an indicator of stress in the marine benthos. Mar. Ecol. Prog. Ser. 295, 91-103. doi: 10.3354/meps 295091

King, P., Kennedy, H., Newton, P. P., Jickells, T. D., Brand, T., Calverte, S., et al. (1998). Analysis of total and organic carbon and total nitrogen in settling oceanic particles and a marine sediment: an interlaboratory comparison. Mar. Chem. 60, 203-216. doi: 10.1016/s0304-4203(97)00106-0

Kutti, T., Hansen, P. K., Ervik, A., Hoisaeter, T., and Johannessen, P. (2007). Effects of organic effluents from a salmon farm on a fjord system. II temporal and spatial patterns in infauna community composition. Aquaculture 262, 355-366. doi: 10.1016/j.aquaculture.2006.10.008

Kvassnes, A. J. S., and Iversen, E. (2013). Waste sites from mines in Norwegian Fjords. Mineralproduksjon 3, A27-A38.

Kvassnes, A. J. S., Sweetman, A. K., Iversen, E. R., and Skei, J. (2009). "Sustainable use and future of submarine tailings placements in the norwegian extractive industry," in Proceedings for the International Conference on Acid-Rock Drainage (ICARD), Vol. 1, (Stockholm: Swedish Association of Mines, Mineral and Metal Producers), 1143-1149.

Kvassnes, A. J. S., Sweetman, A. K., Thorseth, I. H., Hobaek, A., and Bolam, S. (2011). "ImpTail: Improved submarine tailing placements (STPs) in norwegian fjords," in Proceedings for the International Conference on Acid-Rock Drainage.

Laselle, M. W., Landin, M. C., and Sims, J. G. (1991). Evaluation of the flora and fauna of a Spartina alterniflora marsh established on dredged material in Winyah Bay, South Carolina. Wetlands 11, 191-208. doi: 10.1007/bf03160849

Mayer, L. M. (1994). Surface area control of organic carbon accumulation in continental shelf sediments. Geochim. Cosmochim. Acta. 58, 1271-1284. doi: 10.1016/0016-7037(94)90381-6

Mevenkamp, L., Stratmann, T., Guilini, K., Moodley, L., van Oevelen, D., Vanreusel, A., et al. (2017). Impaired short-term functioning of a benthic community from a deep Norwegian fjord following deposition of mine tailings and sediments. Front. Mar. Sci. 4:169. doi: 10.3389/fmars.2017.00169

Middelburg, J. J., Barranguet, C., Boschker, H. T. S., Herman, P. M. J., Moens, T., and Heip, C. H. R. (2000). The fate of intertidal microphytobentos: an in situ ${ }^{13} \mathrm{C}$ labeling study. Limnol. Oceanogr. 45, 1224-1234.

Middelburg, J. J., Klaver, G., Nieuwenhuize, J., Wielemaker, A., de Haas, W., Vlug, T., et al. (1996). Organic matter mineralization in intertidal sediments along an estuarine gradient. Mar. Ecol. Prog. Ser. 132, 157-168. doi: 10.3354/meps132157

Nagelkerken, I., Blaber, S. J. M., Bouillon, S., Green, P., Haywood, M., Kirton, L. G. et al. (2008). The habitat function of mangroves for terrestrial and marine fauna: a review. Aquat. Bot. 89, 155-185. doi: 10.1016/j.aquabot.2007.12.007

Neira, C., Mendoza, G., Porrachia, M., Stransky, C., and Levin, L. A. (2015). Macrofaunal recolonization of copper-contaminated sediments in San Diego Bay. Mar. Pollut. Bull. 101, 794-804. doi: 10.1016/j.marpolbul.2015.09.023

Olsgard, F., and Hasle, J. R. (1993). Impact of waste from titanium mining on benthic fauna. J. Exp. Mar. Biol. Ecol. 172, 185-213. doi: 10.1016/0022-0981(93) 90097-8

Pearson, T. H., and Rosenberg, R. (1978). Macrobenthic succession in relation to organic enrichment and pollution of the marine environment. Ann. Rev. Oceanogr. Mar. Biol. 16, 229-311.

Pearson, T. H., and Stanley, S. O. (1979). Comparative measurement of the redox potential of marine sediments as a rapid means of assessing the effect of organic pollution. Mar. Biol. 53, 371-379. doi: 10.1007/BF00391620

Posey, M. H., Alphin, T. D., and Powell, C. M. (1997). Plant and infaunal communities associated with a created marsh. Estuaries 20, 42-47.

Ramirez-Llodra, E., Trannum, H. C., Evenset, A., Levin, L. A., Andersson, M., Finne, T. E., et al. (2015). Submarine and deep-sea mine tailing placements: a review of current practices, environmental issues, natural analogs and knowledge gaps in Norway and internationally. Mar. Pollut. Bull. 97, 13-35. doi: 10.1016/j.marpolbul.2015.05.062

Ray, G. L., Clarke, D. G., Wilber, T. P., and Fredette, T. J. (1994). Construction of intertidal mudflats as a beneficial use of dredged material. Dredging 94, 946-955.

Robinson, J. E., Newell, R. C., Seiderer, L. J., and Simpson, N. M. (2005). Impacts of aggregate dredging on sediment composition and associated benthic fauna at an offshore dredge site in the southern North Sea. Mar. Environ. Res. 60, 51-68. doi: 10.1016/j.marenvres.2004.09.001 
Sanchez-Moyano, J. E., Estacio, F. J., Garcia-Adiego, E. M., and Garcia-Gomez, J. C. (2004). Dredging impact on the benthic community of an unaltered inlet in southern Spain. Helgol. Mar. Res. 58, 32-39. doi: 10.1007/s10152-003-0166-y

Schrijvers, J., Van Gansbeke, D., and Vincx, M. (1995). Macrobenthic infauna of mangroves and surrounding beaches of Gazi Bay, Kenya. Hydrobiology 306, 53-66. doi: 10.1007/bf00007858

Smit, M. G. D., Holthaus, K. I. E., Trannum, H. C., Neff, J. M., Kjeilen-Eilertsen, G., Jak, R. G., et al. (2008). Species sensitivity distributions for suspended clays, sediment burial, and grain size change in the marine environment. Environ. Toxicol. Chem. 27, 1006-1012. doi: 10.1897/07-339.1

Smith, C. R., and Brumsickle, S. J. (1989). The effects of patch size and substrate isolation on colonization modes and rates in an intertidal sediment. Limnol. Oceanogr. 34, 1263-1277. doi: 10.4319/lo.1989.34.7.1263

Snelgrove, P. V. R., Grassle, J. F., and Petrecca, R. F. (1992). The role of food patches in maintaining high deep-sea diversity: field experiments with hydrodynamically unbiased colonization trays. Limnol. Oceanogr. 37, 15431550. doi: 10.4319/lo.1992.37.7.1543

Sweetman, A. K., Norling, K., Gunderstad, C., Haugland, B. T., and Dale, T. (2014). Benthic ecosystem functioning beneath fish farms in different hydrodynamic environments. Limnol. Oceanogr. 59, 1139-1151. doi: 10.4319/lo.2014.59.4. 1139

Tavares, P. C., Machado, M., and Cancela da Fonseca, L. (2008). Colonization process in soft-bottom macrofauna communities using azoic sediments: comparison of two wetland systems with different organic loads. Fund. Appl. Limnol. 171, 219-232. doi: 10.1127/1863-9135/2008/01 71-0219

Thrush, S. F., and Roper, D. S. (1988). Merits of macrofaunal colonization of intertidal mudflats for pollution monitoring: preliminary study. J. Exp. Mar. Biol. Ecol. 116, 219-233. doi: 10.1016/0022-0981(88) 90028-7

Trannum, H. C., Borgersen, G., Oug, E., Glette, T., Brooks, L., and Ramirez-Llodra, E. (2019). Epifaunal and infaunal responses to submarine mine tailings in a Norwegian fjord. Mar. Pollut. Bull. 149:110560. doi: 10.1016/j.marpolbul.2019. 110560

Trannum, H. C., Gundersen, H., Escudero-Oñate, C., Johansen, J. T., and Schaanning, M. T. (2018). Effects of submarine mine tailings on macrobenthic community structure and ecosystem processes. Sci. Tot. Environ. 630, 189-202. doi: 10.1016/j.scitotenv.2018.02.207

Trannum, H. C., Næss, R., and Gundersen, H. (2020). Macrofaunal colonization of mine tailings impacted sediments. Sci. Tot. Environ. 708:134866. doi: 10.1016/ j.scitotenv.2019.134866

Vogt, C., and Walls, B. (1991). "Environmental effects of dredged material disposal-EPA concerns and regulations," in Proceedings of the 24th Annual Dredging Seminar, (College Station, TX: Texas Engineering Experiment Station), 71-80.

Waldock, R., Rees, H. L., Matthiessen, P., and Pendle, M. A. (1999). Surveys of the benthic infauna of the Crouch Estuary (UK) in relation to TBT contamination. J. Mar. Biol. Assoc. 79, 225-232. doi: 10.1017/s0025315497000258

Whitlatch, R. B., Lohrer, A. M., and Thrush, S. F. (2001). "Scale-dependent recovery of the benthos: effects of larval and post-larval life stages," in OrganismSediment Interactions, eds J. Y. Aller, S. A. Woodin, and R. C. Aller (University of South Carolina Press), 181-197.

Widdicombe, S., and Austen, M. C. (2001). The interaction between physical disturbance and organic enrichment: an important element in structuring benthic communities. Limnol. Oceanogr. 46, 1720-1733. doi: 10.4319/lo.2001. 46.7.1720

Yamamoto, N., and Lopez, G. (1985). Bacterial abundance in relation to surface area and organic content of marine sediments. J. Exp. Mar. Biol. Ecoi. 90, 209-220. doi: 10.1016/0022-0981(85)90167-4

Conflict of Interest: AK is employed by the company ReStone AS.

The remaining authors declare that the research was conducted in the absence of any commercial or financial relationships that could be construed as a potential conflict of interest.

Copyright (C) 2020 Sweetman, Haugland, Kvassnes and Bolam. This is an open-access article distributed under the terms of the Creative Commons Attribution License (CC BY). The use, distribution or reproduction in other forums is permitted, provided the original author(s) and the copyright owner(s) are credited and that the original publication in this journal is cited, in accordance with accepted academic practice. No use, distribution or reproduction is permitted which does not comply with these terms. 